Fall 12-4-2012

\title{
The Lived Experience of Fathers whose Children are Diagnosed with a Genetic Disorder
}

Mary T. Rivard

Follow this and additional works at: https://scholarworks.uttyler.edu/nursing_grad Part of the Nursing Commons

\section{Recommended Citation}

Rivard, Mary T., "The Lived Experience of Fathers whose Children are Diagnosed with a Genetic Disorder" (2012). Nursing Theses and Dissertations. Paper 12.

http://hdl.handle.net/10950/100 
Mary T. Rivard

RNC-OB, Ph.D 


\title{
THE LIVED EXPERIENCE OF FATHERS WHOSE CHILDREN ARE DIAGNOSED \\ WITH A GENETIC DISORDER
}

\author{
by
}

MARY T. RIVARD

A dissertation submitted in partial fulfillment

of the requirements for the degree of

Doctor of Philosophy

Department of Nursing

Beth Mastel-Smith, Ph.D., Committee Chair

College of Nursing and Health Sciences

The University of Texas at Tyler

November 2012 
The University of Texas at Tyler

Tyler, Texas

This is to certify that the Doctoral Dissertation of

\section{MARY T. RIVARD}

has been approved for the dissertation requirement on

November 16, 2012

for the degree of Doctor of Philosophy in Nursing.

Approvals:

Beth Mastel-Smith

Dissertation Chair: (Beth Mastel-Smith, Ph.D.)
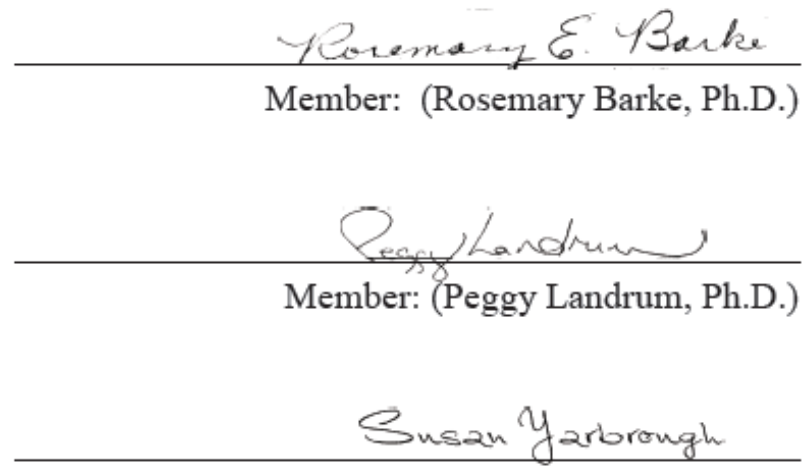

Member: (Susan Yarbrough, Ph.D.)

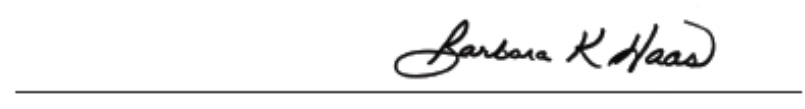

Chair, Department of Nursing

$\checkmark$. Sutt Margille

Dean, College of Nursing and Health Sciences 


\section{Copyright}

(C) Copyright by Mary T. Rivard, 2012

All rights reserved 


\section{Acknowledgments}

This work would not have been possible without the support of my family. To my husband, Dennis and my children, Chris, Amy, Kimberly, Cori, Sam, Emily, Jacobi, and Josh, the numerous nights of eating leftovers and talking softly have now ended. It's time to have some fun.

A much deserved thank-you to my dissertation chair, Dr. Beth Mastel-Smith, for her ability to keep me calm in the midst of chaos when things were not going as planned. You always had a great idea to help work through any problems.

Thank-you also to my dissertation committee and the $\mathrm{PhD}$ in Nursing faculty at the University of Texas at Tyler. I have never come across so many wonderful people who were always willing to help. There is and never will be another program as great as this. 


\section{Table of Contents}

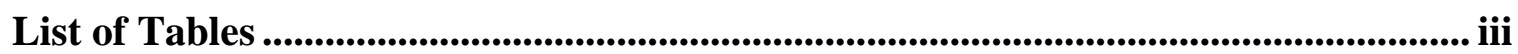

Abstract................................................................................................................................................... iv

Chapter 1: Overview of the Research Study ............................................................................1

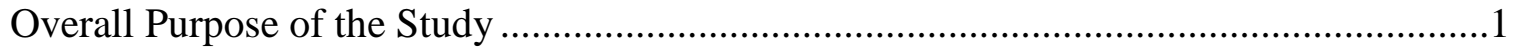
Introduction of Articles Appended ..............................................................................

Results of original research in manuscript format ..................................................................3

Chapter 2 .......................................................................................................................................3

Pattern, A Concept Analysis in the Context of Genetic Development and

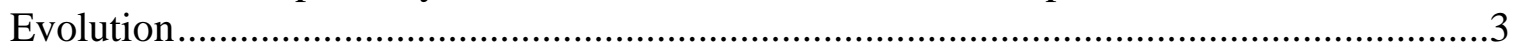

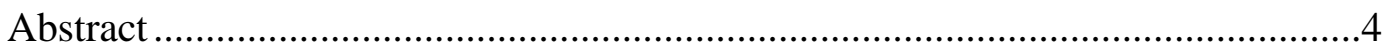

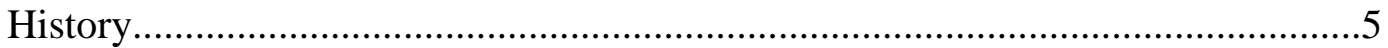

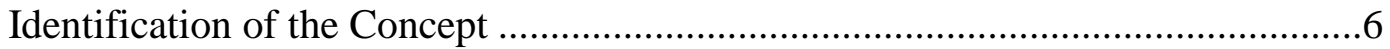

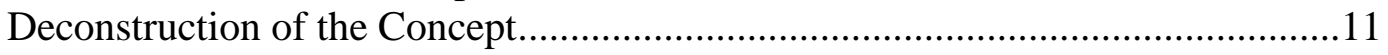

Defining Attributes ...........................................................................12

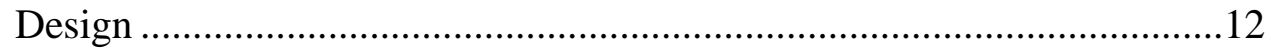

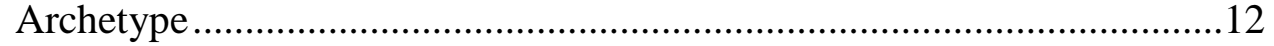

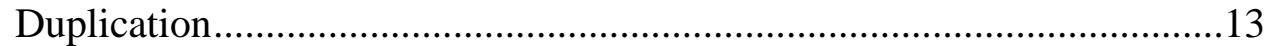

Consistency within the individual...........................................................13

Evolutionary change …………………………………......................14

Antecedents and Consequences ...................................................................14

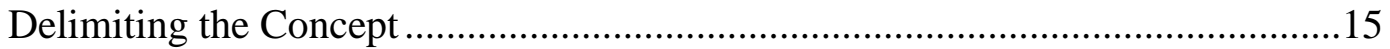

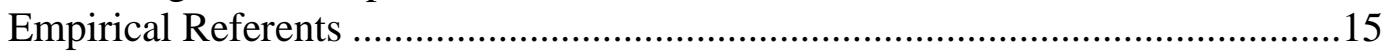

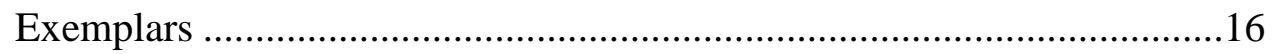

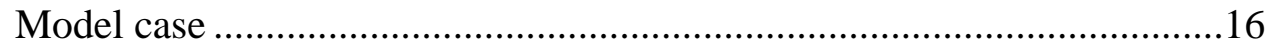

Borderline case..............................................................................17

Related case ..................................................................................

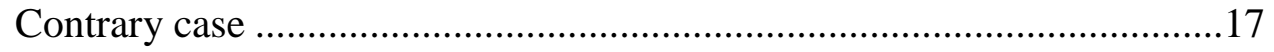

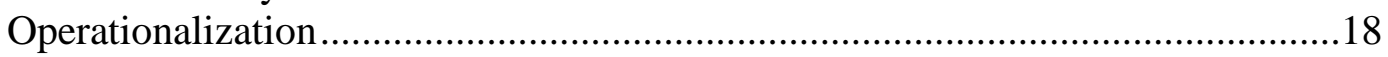

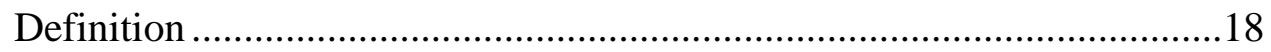

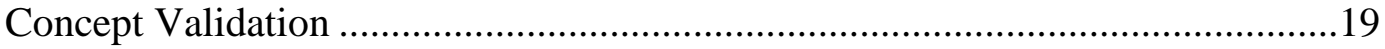

Relevance to Nursing ........................................................................19

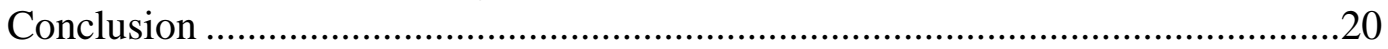

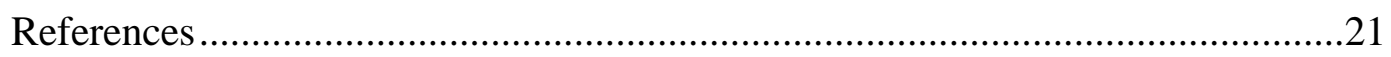

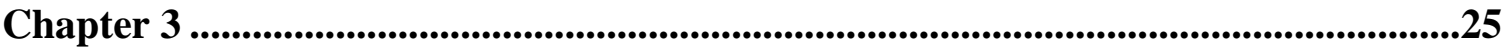

The Lived Experience of Fathers Whose Children are Diagnosed with a Genetic

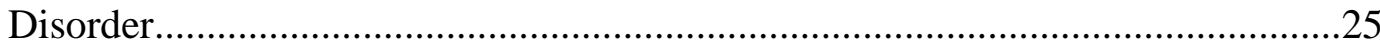

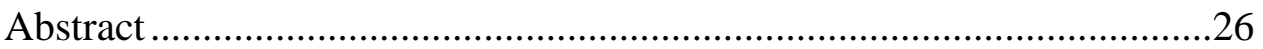

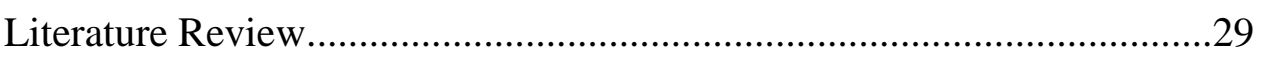

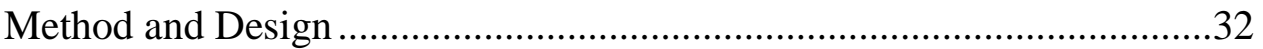

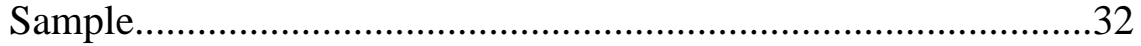

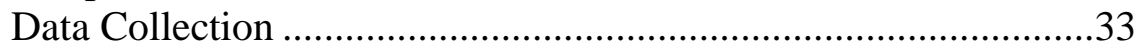


Data Analysis ........................................................................33

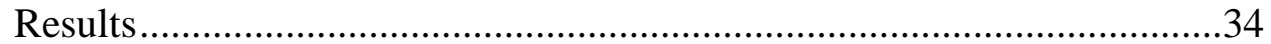

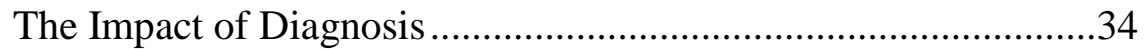

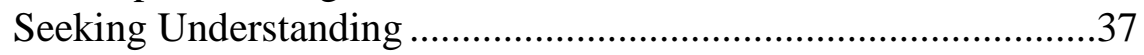

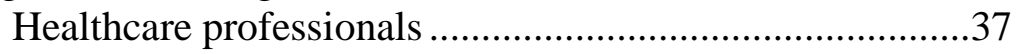

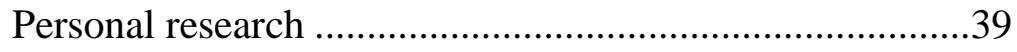

Effect of Time ...............................................................40

Coping with Effects of the Disorder ............................................41

Maintaining the marital relationship ................................41

Adjustment to caring for the child's special needs ............42

Advocating for and teaching others about the

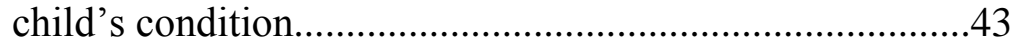

Looking to the Future.............................................................43

What to expect ............................................................43

Reaching out to others for support .................................44

Uncertainty about having other children..........................44

Addressing a Father's Needs ....................................................45

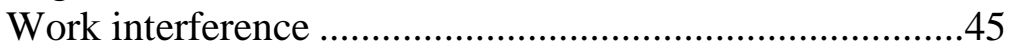

Supporting dad .........................................................46

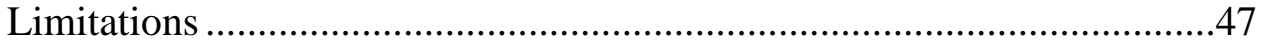

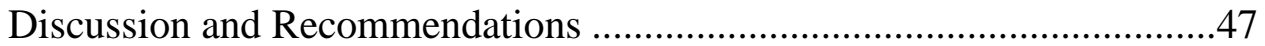

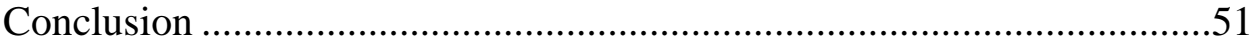

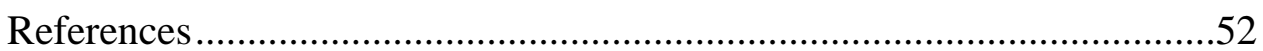

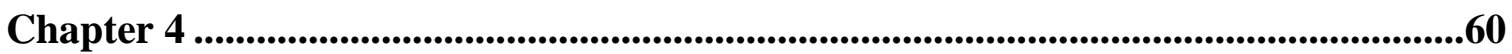

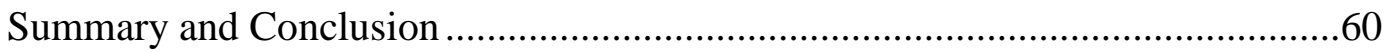

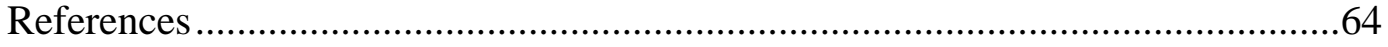

\section{Appendices}

Appendix A Detailed Research Procedure Protocol ........................................65

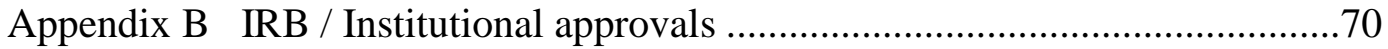

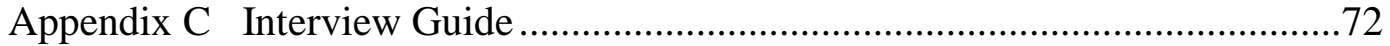

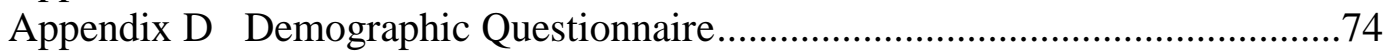

Appendix E Consent Form........................................................................77

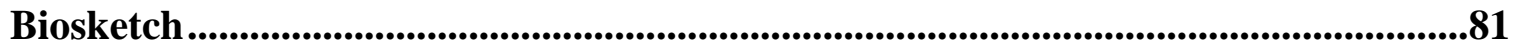




\section{List of Tables}

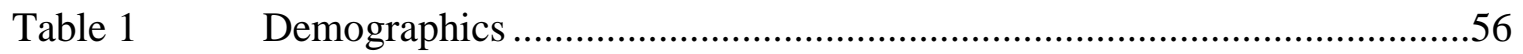

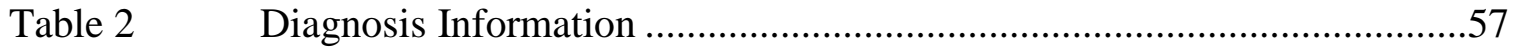




\begin{abstract}
THE LIVED EXPERIENCE OF FATHERS WHOSE CHILDREN ARE DIAGNOSED WITH A GENETIC DISORDER

Mary T. Rivard

The University of Texas at Tyler

December 2012
\end{abstract}

Parenting a child with a genetic disorder requires overcoming numerous obstacles. In the past, research has focused on maternal aspects of childrearing including raising a child with special needs; little consideration for the father's needs has been investigated. To provide optimum care for families whose child has been diagnosed with a genetic disorder, it is necessary to understand the experiences of all those involved in the parenting process. The purpose of this study was to understand the experience of fathers whose children have been diagnosed with a genetic disorder. By gaining insight into a father's reactions and needs, nurses will be better able to provide anticipatory guidance, emotional support, assistance with stressor identification, development of coping mechanisms, and problem solving strategies to assist him in coping with his child's condition. 
Overview of the Research Study

\section{Overall Purpose of the Study}

The purpose of this study is to discuss pattern as it relates to health and genetics and the impact of pattern variations on health. The concept of pattern is evident in many areas of human existence, from the pattern of deoxyribonucleic acid (DNA) structure to parenting and psychological patterns. This portfolio includes two manuscripts, Pattern, A Concept Analysis in the Context of Genetic Development and Evolution and The Lived Experience of Fathers Whose Children are Diagnosed with a Genetic Disorder.

The focus of each manuscript is to provide insight into the existence of patterns and impact of variations in genetic patterns. The first, a concept analysis, describes patterns of human existence and their relationship to health while the second describes patterns of reaction and experience among fathers whose children are diagnosed with genetic disorders. Understanding patterns and the impact of pattern alterations informs nursing interventions aimed at prevention and/or treatment.

\section{Introduction of Articles Appended}

This portfolio is comprised of two articles. The first article, Pattern, A Concept Analysis in the Context of Genetic Development and Evolution, describes the concept of pattern with a focus on its relationship to genetics and evolution. Without pattern, chaos is inevitable. Chaos causes the human body to undergo changes that lead to disease and disorder. Understanding genetic, behavioral, activity, and environmental patterns and their effects on the human body might assist nurses and other healthcare providers in 
halting the progress of conditions that could result in years of burdensome care and/or death.

The second article, The Lived Experience of Fathers Whose Children are Diagnosed with a Genetic Disorder, is the report of a phenomenologic study, the aim of which was to find meaning in fathers' experiences of discovering their child has a genetic disorder. Past research focused on maternal reactions to issues of child health and care. Little recognition was been paid to fathers' experience at the time of their child's diagnosis and their role in child care, resulting in a lack of information and understanding about fathers' needs. When a child is diagnosed with a genetic disorder, the father must learn to deal with the repercussions, further increasing the necessity for nurses and other healthcare professionals to understand his needs. The findings inform nurses regarding how to assist fathers at the time of the child's diagnosis and in managing the challenges of parenting his child. 
Title: Pattern, A Concept Analysis in the Context of Genetic Development and Evolution Author Information:

Mary T. Rivard

Degree: MSN; Certifications: Inpatient Obstetrics

Title: PhD Student, The University of Texas at Tyler, Tyler, Texas

Associate Degree Nursing Faculty, Vernon College, Vernon, Texas

Email: mrivard@patriots.uttyler.edu

Name: Beth Mastel-Smith

Degrees: BSN, MS, PhD

Title: Associate Professor, The University of Texas at Tyler

Email: bethms@swbell.net

Correspondence to be sent to:

Mary T. Rivard

1929 Perigo

Wichita Falls, TX 76301

Phone: (940) 723-4090

Fax: (940) 322-3707

Email: mrivard@patriots.uttyler.edu

No conflict of interest has been declared by the author(s).

This research received no specific grant from any funding agency in the public, commercial, or not-for-profit sectors. 


\begin{abstract}
The concept of pattern refers to a design used for replication of an original model or archetype. In humans, patterns are evident from conception to death beginning with the pattern of human deoxyribonucleic acid (DNA). DNA is the basis for creation and development of every individual. Understanding the concept of pattern, as it pertains to genetics, and its relationship to development, health, and illness is an essential component to comprehending the importance of supporting genetic knowledge in nursing. Advancing this knowledge has the potential to assist nurses in improving prevention, diagnosis, and treatment of genetic anomalies.
\end{abstract}

Keywords: pattern, genetics, genomics, DNA, concept analysis 
The beauty and complexity of patterns have frequently been discussed among artists and scientists alike. The pattern of an artistic masterpiece or the rhythmical pattern of a musical composition can have a great effect on a person. The pattern of a mathematical equation can be used to predict outcomes of other patterns such as the manner in which the planets and galaxies rotate, orbit, and move through the universe. By recognizing such patterns and their impact on humanity, people are better able to predict and interpret their existence.

In nursing, the ability to recognize pattern is essential to providing optimal patient care because it provides the opportunity to identify situations that may affect an individual's health before a problem is evident or recognize patterns of negative or positive outcomes. The pattern of human DNA is one such example where any disruption, even minor, might result in detrimental effects.

\section{History}

The history of pattern can be traced back to the "Big Bang," the beginning of what is known as time. With the creation of the universe, patterns of "ripples" resulted in the congregation of galaxies. These ripples expanded through time and space; they helped to create matter, the universe, DNA, and life as it is commonly known (Irion, 2005).

As time progressed, many disciplines have acknowledged patterns. Patterns are seen in nature, architecture, clothing, art, and numerous other venues. Patterns can be recognized in the genetic makeup of all living organisms, changing and progressing as necessary through the process of evolution. While many of these patterns are naturally occurring, others have been developed and used to enhance the human experience. 


\section{Identification of the Concept}

The definition of pattern is dependent on the context of its application. For purposes of this analysis, the definition will be limited to its use as a noun. The following databases were searched for examples of pattern: CINAHL, Medline/Pubmed, Science Direct, Nursing Collection I and Premiere Collection, Springerlink, Wiley Online Library, Science and Technology Collection, and Academic Search Complete. Definitions and references to pattern were noted in the disciplines of nursing, genetics, human development, medicine, psychology, epidemiology, chemistry, sewing, mathematics, astronomy, sociology, migration, criminology, physics, meteorology/climatology, and statistics.

Dictionary.com defines pattern as an original model used to create copies or as a design that is natural or accidental in nature (pattern, n.d.). This description is useful in its application to the human reproductive process and/or the genetic makeup of a human being. Pattern is also defined (pattern, n.d.) as a group of traits or characteristics of individuals or groups. This definition further describes the process of genetic transmission of characteristics as well as psychological adaptation to health and illness, such as patterns of behavior or attitude. Following are descriptions of pattern as utilized in various fields.

Mathematics has frequently been described as the "Science of Pattern" in that numbers themselves can be used to develop designs such as with even and odd patterns or the arrangement of a set of prime numbers. Patterns can be seen in mathematical equations and may occasionally involve series' of other equations to form even more intricate designs (Devlin, 1997). Algebraic and geometric patterns are evident in their 
equations and theorems. Combining equations to create even more intricate arrangements results in evolving patterns (Devlin, 1997). The concept of fractals has been described as mathematical patterns where geometric shapes repeat themselves in smaller and smaller forms while retaining their original shape. These fractals are being recognized in many areas of the human design including lung and cardiac tissue (Krstacic, Krstacic, Smalcelj, Milicic, \& Jembrek-Gostovic, 2007; Vicenzi, 1994), and in DNA fragments (Nicolay et al., 2007). Vicenzi (1994) posits, "higher fractal dimensions may (help to) describe more complex and more variable unitary phenomena" (1994, p. $41)$.

In astronomy, pattern is seen in the distribution of the galaxies, the orbits of planets, moons, and debris, and in the configuration of solar systems (Irion, 2005). Meteorological science describes weather patterns, including seasonal patterns. These patterns play an important role in the ecological development of the planet. Alterations in these patterns cause the Earth to exhibit changes in its ability to produce and sustain life. One such pattern is that of "El Niño" where increased precipitation may lead to blizzards and flooding (Larson, 2004). Recognition of weather patterns allows for prediction of weather related events thereby improving forecast ability (Root, Knight, Young, \& Greybush, 2007) and disaster preparedness.

Patterns have also been noted in chemistry. De Lacy, Costello, Jahan, Adamatzky, and Ratcliffe (2009) described patterns in their report of the properties of certain chemical reactions. In their work with various metal ions, tessellating or mosaic patterns were noted when these ions where combined. Chemicals themselves may be 
seen as patterns of molecular combinations resulting in inherent properties, each with its own unique makeup, qualities, and uses.

Patterns of migration have long been documented in the animal kingdom. These patterns may necessarily change over time to meet the needs of the species. As climates and conditions change animal populations move and patterns adjust to encourage survival of the species (Wilcove, 2008). Even the human population has demonstrated migration patterns in its tendency to congregate in areas where food, water, shelter, and employment are plentiful.

Social and cultural variations may also be recognized as patterns. This is evident in practices and beliefs of differing groups, such as the pattern of prayer in the Muslim religion or the eating patterns of individual family systems that can result in obesity (Delormier, Frohlich, \& Potvin, 2009; Lawrence \& Rozmus, 2001). In nursing, cultural patterns have been noted in the way differing groups react to and deal with pain. For example, the pain of labor may result in vocal distress or stoicism depending on a woman's cultural norms (Perry, Hockenberry, Lowdermilk, \& Wilson, 2010). Awareness of cultural diversity requires nurses to develop their understanding of cultural norms to care for individual groups (Narayan, 2010).

Among differing racial or ethnic groups, variation in genetic pattern is evident. This may result in an affinity for specific disease processes such as increased risk for hypertension among those of African ancestry or Tay Sachs disease in individuals of Jewish descent. Although patterns may vary among distinct racial or ethnic groups, the underlying human pattern remains (Huether \& McCance, 2008). 
In research, statistical patterns are examined and utilized as a means for predicting outcomes. One example is the manipulation of data to form frequency distributions which are often described in terms of the curvilinear pattern they produce. Probability distributions can be determined based on the form of the frequency distribution, providing a means to calculate the likelihood of a specific score occurring within the shape of a curvilinear pattern (Field, 2009).

Epidemiology has been described as "a science of pattern" (Waggoner \& Aylor, 2000, p. 71) where scientists study disease frequency and distribution. Understanding the pattern in which disease occurs can aid in prediction and prevention of further infection and/or outbreaks by concentrating on the whole picture of a malady's occurrence rather than a specific case. Many diseases themselves follow predictable patterns of infection from time of exposure to symptom development and duration of illness. Symptoms themselves may also follow a pattern. For example, the lesion associated with tinea corporis typically follows a ring-like pattern hence the term "ringworm" to identify the infection (Huether \& McCance, 2008).

In physics, wave patterns are a frequently discussed phenomenon. Wave patterns are recognized in the movement of water across the ocean floor (Reikard \& Rogers, 2011) as well as being associated with electricity, electromagnetic fields, gravity, and seismic activity. Each of these wave patterns is linked in some way to energy production and its dispersal (Hosokawa et al., 2011; Strobel, 2011; wave, n.d.). These patterns can often be predicted based on the medium and surrounding conditions, both of which have a profound effect on the maintenance and/or disruption of the pattern. 
Wave patterns are also recognized in the medical discipline. Brain wave patterns, a form of electrical neural activity, have been recognized and can be affected by disruptions in normal conduction resulting in misfiring and possible seizure activity (Ursino \& La Cara, 2006). Wave patterns are also seen in the conduction system of the myocardium. Using available technology such as electroencephalography (EEG) and electrocardiography (ECG) these wave patterns can be analyzed to assist in differentiation of normal or abnormal configurations that might result in illness (Huether \& McCance, 2008).

In humans, the developmental process includes physical and psychosocial patterns. Developmental patterns can be seen as early as embryonic life. Larsen (2001) states, "the spatial organization of differentiating cells and tissues, which accounts for the morphogenesis of the organs and, ultimately, of the body as a whole, is called pattern formation" (p. 335). Trunk and neural crest differentiation as well as visceral development are all processes of pattern formation in the embryo. Growth patterns in children take place in cephalocaudal and proximodistal patterns. The process of aging also follows a pattern. As humans age, normal body processes meant to support growth and sustain life slow and/or cease resulting in changes that eventually lead to disorder and death. Although the process is distinctive to each individual the pattern in humans remains constant.

Psychosocial maturation is expected to follow patterns or stages such as those described by Erikson (Perry, et al., 2010) where each stage of the pattern influences a person's progression to the next level. If a person does not complete a part of the pattern, they may be unable to effectively function in society (Berman \& Snyder, 2012). 
Medical and scientific communities have recognized biorhythmic patterns in humans and other biologic species. Humans operate according to circadian rhythms which regulate many aspects of body function. These patterns affect functions such as temperature regulation, blood pressure, and sleep. When these rhythms are disrupted, dysfunction can result leading to illness and/or disorder including sudden infant death syndrome, hypotension, and sleep disturbances (Hassler \& Burnier, 2005; Thomas \& Burr, 2006). Health care professionals use this knowledge in order to manage and care for individuals with issues related to circadian rhythms by adjusting medications and/or planning care around the knowledge that these patterns occur.

The computer sciences have developed pattern recognition software to identify configurations of many different data patterns. These include medical, speech recognition, and statistical patterns, to name a few (pattern recognition, 2010). Pattern recognition has been a major topic among computer scientists and is described (Howe, 2010) as "a branch of artificial intelligence concerned with the classification or description of observations. Pattern recognition aims to classify data (patterns) based on either a priori knowledge or on statistical information extracted from the patterns" (computing dictionary, para. 1).

The use of pattern is seen in many areas. Its characteristics depend on the context. Pattern changes and evolves with time or the risk of extinction becomes a certainty. The transformation may become more complex or simplified depending on its purpose but, the expected result is survival. 


\section{Deconstruction of Concept}

\section{Defining Attributes}

Identification of defining attributes is necessary to provide an understanding of a concept's application. This identification provides a valid and functional explanation of the concept's definition in relation to the proposed context (Balwin, 2008; Rodgers \& Knafl, 2000). Following are the defining attributes of pattern as they apply to human genetics.

\section{Design}

Before a pattern can be created, it must be designed. This design or plan is essential for identifying the purpose and function of the pattern. It provides the underlying framework to build upon. Human DNA contains many attributes distinctive to the species yet the basic design of every human being is the same. Humans share many DNA attributes with other mammalian species but only relatively small differences resulted in the uniquely human design (McLean et al., 2011; Pääbo, 1999).

\section{Archetype}

For pattern to manifest, an archetype is necessary. This original pattern, model, or prototype becomes the basis for all copies. An archetype generally represents the ideal configuration of a design, exemplifying its attributes and identifying its limits (archetype, 2009). In human genetics, the archetype would be considered the first complete cell of each new individual, the zygote produced by fertilization of the ova at conception. This cell will continue to divide and differentiate resulting in the unique attributes of the individual (Larsen, 2001). 


\section{Duplication}

Duplication is a consequence of pattern development. Without duplication, pattern does not have purpose. Cells must divide, differentiate, and duplicate to create the pattern of organs and tissues.

\section{Consistency within the Individual}

Pattern consistency is essential to obtaining accurate duplication. Although the cells will differentiate into diverse organ systems and tissues, the structure of genetic material generally remains the same. When consistency within the individual is absent or altered, the final product will not be an accurate representation of the original. This alteration can lead to changes that might, ultimately, result in degradation of the original intent of the pattern design. Exposure to teratogens such as radiation or viruses can cause alteration in an individual's DNA structure and result in disease and/or death (Huether \& McCance, 2008). For the human body to develop and maintain normal function, the pattern of cell division must remain relatively consistent. As a person ages and/or pattern loss occurs, disease and disorder result.

In many individuals, genetic predisposition for disease is present from birth. While disorders with a genetic component, such as inherited cases of Alzheimer's disease (AD) and some cancers such as those associated with the BRCA (breast cancer) gene, may produce illness, the conditions usually do not occur until later in life. However, the pattern of duplication remains consistent throughout the person's life but, until the evidence of the trait emerges, no observable indication of genetic anomaly is present (Ulrich, Wallen, \& Grady, 2008). In other instances of AD, certain cancers, and many 
other disorders, genetic mutations occur as a person ages. In these cases the genetic pattern changes through an individual's lifetime resulting in disease (Hinds et al., 2005).

Although contradictory to this attribute, occasionally small, non-detrimental mutations do occur. Genetic disease happens when the normal function of a gene is disrupted (U.S. Department of Energy, 2011). Genetic disorders often require multiple mutations before becoming evident (Hinds, et al., 2005). According to Freeland and Hurst, a small change in a single gene may be beneficial if it allows an organism to perform better in the environment (2004). Therefore, mutations do not always result in disease but instead, may ultimately be part of the evolutionary process.

\section{Evolutionary Change}

Through the process of evolution, a pattern might change to meet the demands of present circumstances. Without this change, what may have started as an ideal archetype becomes obsolete as it does not meet the needs of the current situation. In genetics, these changes occur over time as organisms attempt to adapt to changes in the environment. Multiple mutations result in genotypic and phenotypic changes that provide for survival of the species (Gompel \& Prud'homme, 2009). Evolutionary change is not a process that occurs quickly. Survival depends on the mutation being purposeful and not immediately detrimental to the organism.

\section{Antecedents and Consequences}

Before pattern can manifest, there must be a need or purpose. This need or purpose will define how the pattern is designed or planned resulting in an archetype. Once the archetype has been created, duplication becomes possible. 
As a result of duplication, creation ensues. This pattern duplication, if consistent, results in regular, predictable reproductions that will eventually transform, as necessary, through the process of evolution.

\section{Delimiting the Concept}

\section{Empirical Referents}

The significance of pattern is evident with an understanding of the consequences related to absence of pattern. Without pattern, chaos would be rampant. There is evidence of chaos in areas where pattern does not exist or where the original pattern has become significantly altered. Chaos may be seen in crowded areas where the rules of acceptable behavior are not followed resulting in mass confusion and sometimes, violence. In this situation, any disruption, for example, someone yells "fire," can trigger negative consequences. However, if the pattern of accepted behavior is respected, generally events proceed in an orderly fashion.

Chaos in the human body can also be observed. Even at the most basic genetic level, patterns are apparent. DNA develops and replicates in a double helix pattern arranged in sequences where cytosine has an affinity to guanine and thymine to adenine. When these sequences are disrupted, chaos results and anomalies abound. Chromosome number and structure must also maintain their original pattern or risk the development of still more unwelcome consequences. The effect of teratogenic agents such as radiation, viruses, or bacterium can place the individual at risk for development of chaotic change resulting in disease and/or disorder.

Pattern might also be recognized in the manner in which the heart beats or muscles contract. When the normal pattern of electrical impulse is disrupted, muscle 
movement, including that of the myocardium, is disrupted and can result in damage. During the process of labor, absence of an adequate uterine contraction pattern results in dysfunction and may require surgical delivery of the fetus.

Pattern and chaos are both part of the human condition. Without the two working with and against each other, humans may have evolved into something entirely different from the current form.

\section{Exemplars}

\section{Model Case}

M.M., 37 years old, is pregnant with her first child. She has chosen to have an amniocentesis to check for genetic anomalies due to advanced maternal age. Neither M.M. nor her husband has a family history of genetic anomalies. The karyotype, or pictorial representation of the fetus' chromosome number, size, and form, is returned and shows a normal 46, XY configuration without evidence of genetic anomalies. M.M. gives birth to a healthy male infant at 39 weeks gestation.

The basic design for the creation of a new human comes from the human genome. This genome adapts and changes from person to person, but the basic components remain intact. The archetype for the new human comes from the pairing of parental genetic material. All copies of chromosome number and sequence must conform to this original for the child to remain healthy. This archetype will be duplicated on a continuous basis throughout the child's lifetime resulting in creation and maintenance of organs and tissues. The child does not have the same pattern as the parents but rather a combination and intermingling of the two. 


\section{Borderline Case}

P.D., a 2 week old infant, was delivered at term. His parents were karyotypically normal and denied any history of genetic anomaly in their families. No genetic testing was done prior to delivery. On newborn assessment the nurse noted low-set ears and decreased muscle tone. Following notification of the physician and discussion with the parents, genetic testing was performed. P.D.'s karyotype revealed mosaic Down Syndrome. In cases of mosaicism, some cells possess a normal karyotype while others do not. Although P.D. had a human design and began with a normal archetype, at some time during cell duplication, consistency of the pattern in some cells was disrupted while in others, consistency remained intact.

\section{Related Case}

C.B., a female infant, was born by spontaneous vaginal delivery. She appeared normal and healthy at birth. C.B.'s mother has brown hair, her father has blonde hair, and C.B. has red hair.

Although C.B. was a normal, healthy newborn with all the attributes expected in a human offspring, her red hair does not appear to have followed the genetic pattern expected from the combination of her parent's DNA but, may well be due to recessive genes received from both parents. Although it is possible to have a child with qualities not apparent in the parents, without genetic testing, one might question whether the father was truly the one who provided the genetic material for the creation of C.B.

\section{Contrary Case}

B.D., whose gender was unidentifiable at birth, was delivered by emergency cesarean section for breech presentation and atypical fetal heart rate pattern at 28 weeks 
gestation. There was no history of genetic anomaly in the parent's families. One hour prior to birth, B.D.'s mother arrived to the labor and delivery unit in preterm labor. Prior to delivery, B.D.'s baseline heart rate was 90 beats per minute and decreasing.

At delivery, B.D. was noted to be in asystole and without respiratory effort.

Multiple external anomalies were noted on exam. Due to the extent of the malformations, the pediatrician and parents opted not to resuscitate. Karyotype done at autopsy revealed multiple genetic defects considered incompatible with life.

In this case, it appeared the design of B.D. was flawed at conception. This flaw resulted in a genetic archetype that was incompatible with life. While duplication occurred, it is unclear as to whether the original genetic defect caused this to happen in a typical pattern and/or whether duplication was consistent following conception.

\section{Operationalization}

\section{Definition}

This operational definition of pattern has been created based on the aforementioned defining attributes: design, archetype, duplication, consistency within the individual, and evolutionary change.

a. A design is evident as a basis for creation of the pattern.

b. An archetype is created at the moment of pattern conception.

c. The archetype pattern remains consistent throughout the process of duplication.

d. As the pattern evolves, changes occur to meet the needs of the species.

These attributes can be measured by examination of the karyotype of individual cells. 


\section{Concept Validation}

Concept validation refers to the relevance of a concept to its proposed purpose, in this case, the relevance of pattern to nursing.

\section{Relevance to Nursing}

An understanding of pattern is relevant to nursing in several ways. Pattern recognition is essential to addressing client needs. First, because genetic pattern is the basis for all human development, knowledge of its meaning and purpose is essential to providing holistic care to the individual. Second, recognition of pattern alteration may alert the nurse to potential changes in the condition of an individual, including physical and/or psychological issues, thereby allowing for timely intervention. Third, with proper understanding of pattern and environmental interactions, the nurse has the opportunity to provide education to individuals at risk for development of disorders related to pattern change. Finally, by understanding that some change in pattern is necessary to promote survival of the individual and the species, nurse researchers can identify how these changes occur, what promotes or discourages these transformations, and the ultimate effect on the population.

Pattern recognition might also assist nurses to improve clinical outcomes by creating an opportunity to stop and/or limit the effects of disease processes through the use of prevention strategies. Tracking pattern change through epidemiological approaches can help to evaluate prevention efforts for example, the numbers of newborns with genetic anomalies or adults at risk for genetic dysfunction. 


\section{Conclusion}

Without pattern, the world would be in a state of constant chaos. Patterns are evident in every corner of the universe, from the smallest microbe to the largest galaxy. Through awareness of the reason for patterns' existence and an understanding of their meaning and usefulness, humanity has the potential to greatly increase insight into the workings of the human body from the level of DNA through the whole of human subsistence.

With an understanding of underlying genetic, behavior, activity, and environmental patterns, and their effects on the human body, it might be possible to halt the progress of many conditions that, in the past, have resulted in years of burdensome care or imminent death. This understanding might allow the medical community to recognize detrimental alterations early in the process of their development. Intervention can be delivered quickly before damage occurs or increases. With further study and recognition of effective treatment, persons with genetic disorders may experience improved quality of life and eventually, a cure. Study of these patterns is essential to understanding their effects and creating successful preventative and/or treatment modalities. Through detection of patterns related to improvement or deterioration in the healthcare consumer's condition, nurses have the opportunity to make preemptive strikes that could ultimately result in improved patient outcomes. 


\section{References}

archetype. (2009). Available from Dictionary.com The American Heritage Dictionary of the English Language, Fourth Edition Retrieved February 6, 2010, from The American Heritage Dictionary of the English Language, Fourth Edition http://dictionary.reference.com/browse/archetype $? \mathrm{o}=100084 \& q \mathrm{src}=2871 \& \mathrm{l}=\mathrm{dir}$

Baldwin, M. A. (2008). Concept analysis as a method of inquiry. Nurse Researcher, 15(2), 49-58.

Berman, A., \& Snyder, S. (2012). Fundamentals of nursing (9th ed.). Boston: Pearson.

De Lacy-Costello, B. P. J., Jahan, I., Adamatzky, A., \& Ratcliffe, N. M. (2009). Chemical tessellations. International Journal of Bifurcation \& Chaos in Applied Sciences \& Engineering, 19(2), 619-622. doi: 10.1142/S0218127409023238

Delormier, T., Frohlich, K. L., \& Potvin, L. (2009). Food and eating as social practice - understanding eating patterns as social phenomena and implications for public health. Sociology of Health \& Illness, 31(2), 215-228. doi: 10.1111/j.14679566.2008.01128.x

Devlin, K. (1997). Mathematics, The Science of Patterns; The Search for Order in Life, Mind, and the Universe New York: Henry Holt and Company, LLC.

Field, A. (2009). Discovering Statistics Using SPSS. London: Sage.

Freeland, S. J., \& Hurst, L. D. (2004). Evolution encoded: new discoveries about the rules governing how genes encode proteins have revealed nature's sophisticated "programming" for protecting life from catastrophic errors while accelerating evolution[corrected] [published erratum appears in SCI AM 2004 Aug;291(2):12]. Scientific American, 290(4), 84-91.

Gompel, N., \& Prud'homme, B. (2009). The causes of repeated genetic evolution. Developmental Biology, 332(1), 36-47. doi: DOI: 10.1016/j.ydbio.2009.04.040

Hassler, C., \& Burnier, M. (2005). Circadian variations in blood pressure: implications for chronotherapeutics. American Journal of Cardiovascular Drugs, 5(1), 7-15. 
Hinds, D. A., Stuve, L. L., Nilsen, G. B., Halperin, E., Eskin, E., Ballinger, D. G., . . . Cox, D. R. (2005). Whole-genome patterns of common DNA variation in three human populations. Science, 307(5712), 1072-1079. doi:

10.1126/science. 1105436

Hosokawa, T., Kaneda, T., Takahashi, T., Yamamoto, T., Morita, T., \& Sekiya, Y. (2011). DC breakdown characteristics in the gap with thin dielectric sheet in air. [Article]. IEEE Transactions on Dielectrics \& Electrical Insulation, 18(3), 822832. doi: 10.1109/tdei.2011.5931071

Howe, D. (2010). pattern recognition. Available from Dictionary.com Free Online Dictionary of Computing Retrieved September 5, 2011 http://dictionary.reference.com/browse/pattern\%20recognition?o=100084\&qsrc= 2894\&l=dir

Huether, S., \& McCance, K. (2008). Understanding pathophysiology (4th ed.). St. Louis: Mosby.

Irion, R. (2005). Galaxy patterns preserve an imprint of the big bang. Science, 307(5709), 508-508. doi: 10.1126/science.307.5709.508a

Krstacic, G., Krstacic, A., Smalcelj, A., Milicic, D., \& Jembrek-Gostovic, M. (2007). The "Chaos Theory" and nonlinear dynamics in heart rate variability analysis: does it work in short-time series in patients with coronary heart disease? Annals of Noninvasive Electrocardiology, 12(2), 130-136. doi: 10.1111/j.1542474X.2007.00151.x

Larsen, W. (2001). Human embryology (3rd ed.). New York: Churchill Livingstone.

Larson, J. (2004). Understanding global climate patterns. 2010 (February 6). Retrieved from http://www.usatoday.com/weather/climate/2006-04-19-global-climatepatterns_x.htm

Lawrence, P., \& Rozmus, C. (2001). Culturally sensitive care of the Muslim patient. Journal of Transcultural Nursing, 12(3), 228-233. doi: $10.1177 / 104365960101200307$ 
McLean, C. Y., Reno, P. L., Pollen, A. A., Bassan, A. I., Capellini, T. D., Guenther, C., ... Kingsley, D. M. (2011). Human-specific loss of regulatory DNA and the evolution of human-specific traits. Nature, 471(7337), 216-219. doi: 10.1038/nature09774

Narayan, M. C. (2010). Culture's effects on pain assessment and management: cultural patterns influence nurses' and their patients' responses to pain. American Journal of Nursing, 110(4), 38-49. doi: 10.1097/01.NAJ.0000370157.33223.6d

Nicolay, S., Brodie, E. B., Touchon, M., Audit, B., d'Aubenton-Carafa, Y., Thermes, C., \& Arneodo, A. (2007). Bifractality of human DNA strand-asymmetry profiles results from transcription. Physical Review E, 75(3), 032902. doi: 10.1103/PhysRevE.75.032902

Pääbo, S. (1999). Human evolution. Trends in Genetics, 15(12), M13-M16. doi: Doi: 10.1016/s0168-9525(99)01904-6

pattern. (n.d.). Dictionary.com Retrieved January 28, 2010, from The American Heritage Dictionary of the English Language, Fourth Edition http://dictionary.reference.com/browse/pattern

pattern recognition. (2010). Available from Dictionary.com Dictionary.com Unabridged Retrieved February 6, 2010, from The American Heritage Dictionary of the English Language, Fourth Edition http://dictionary.reference.com/browse/pattern+recognition?o=100084\&qsrc=287 $1 \& 1=$ dir

Perry, S., Hockenberry, M., Lowdermilk, D., \& Wilson, D. (2010). Maternal Child Nursing Care. Maryland Heights: Mosby.

Reikard, G., \& Rogers, W. E. (2011). Forecasting ocean waves: Comparing a physicsbased model with statistical models. Coastal Engineering, 58(5), 409-416. doi: 10.1016/j.coastaleng.2010.12.001

Rodgers, B., \& Knafl, K. (2000). Concept Development in Nursing (2nd ed.). Philadelphia: Saunders.

Root, B., Knight, P., Young, G., \& Greybush, S. (2007). A fingerprinting technique for major weather events. Bulletin of the American Meteorological Society, 88(9), 1353-1356. doi: 10.1175/JAM2509.1 
Strobel, B. (2011). Demonstration and study of the dispersion of water waves with a computer-controlled ripple tank. American Journal of Physics, 79(6), 581-590. doi: $10.1119 / 1.3556140$

Thomas, K. A., \& Burr, R. L. (2006). Melatonin level and pattern in postpartum versus nonpregnant nulliparous women. JOGNN: Journal of Obstetric, Gynecologic \& Neonatal Nursing, 35(5), 608-615.

U.S. Department of Energy. (2011). Human genome project information. Retrieved November 11, 2011 http://www.ornl.gov/sci/techresources/Human_Genome/medicine/assist.shtml

Ulrich, C. M., Wallen, G. R., \& Grady, C. (2008). Ethics and genetics: what should every advanced practice nurse know? Clinical Scholars Review, 1(2), 69-71. doi: 10.1891/1939-2095.1.2.69

Ursino, M., \& La Cara, G.-E. (2006). Travelling waves and EEG patterns during epileptic seizure: Analysis with an integrate-and-fire neural network. Journal of Theoretical Biology, 242(1), 171-187. doi: 10.1016/j.jtbi.2006.02.012

Vicenzi, A. E. (1994). Chaos theory and some nursing considerations. Nursing Science Quarterly, 7(1), 36-42. doi: 10.1177/089431849400700112

Waggoner, P. E., \& Aylor, D. E. (2000). Epidemiology: A science of patterns. Annual Review of Phytopathology, 38(1), 71. doi: 10.1146/annurev.phyto.38.1.71

wave. (n.d.). Available from Dictionary.com The American Heritage Science Dictionary Retrieved July 16, 2011, from The American Heritage Science Dictionary http://dictionary.reference.com/cite.html?qh=wave\&ia=ahsd

Wilcove, D. S. (2008). Animal migration: An endangered phenomenon? Issues in Science \& Technology, 24(3), 71-78. doi: 10.1093/icb/31.1.265 
The Lived Experience of Fathers Whose Children are Diagnosed with a Genetic Disorder A Paper

Submitted in Partial Fulfillment of the Requirements for the PhD in Nursing In the College of Nursing

The University of Texas at Tyler

\section{By}

Mary T. Rivard

November, 2012 


\begin{abstract}
Objective: To describe the experience of a child's diagnosis with a genetic disorder the father's perspective.

Design: Interpretive phenomenology

Setting: In person interviews for participants living within 100 miles of the researcher, in a location chosen by the participant; phone interviews with participants living greater than 100 miles from the researcher.
\end{abstract}

Participants: Six fathers of children diagnosed with a genetic disorder.

Methods: Participants recruited with the assistance of nurses, physicians, and genetic counselors. Snowball sampling, internet and email recruitment, and word of mouth were also used. Semi-structured interviews completed, audio recorded, and transcribed verbatim.

Results: Five themes emerged: 1) the impact of diagnosis, 2) seeking understanding, 3) coping with effects of the disorder, 4) looking to the future, and 5) addressing a father's needs.

Conclusion: Fathers of children diagnosed with a genetic disorder described a lack of education and information regarding the diagnosis. They attributed this deficiency to a lack of knowledge among physicians, nurses, and other healthcare professionals. Coping with the effects of the disorder were identified as an integral part of adapting to meet the child's needs. Concerns about the child's future and effects on the family were also discussed. Fathers also described feeling left out of discussions and being unable to stay involved in their child's care because of employment schedules. Understanding the experience of a father whose child is diagnosed with a genetic disorder is necessary to ensure provision of proper intervention and care. 
Keywords: genetics, genomics, fathers, children with genetic disorders, phenomenology, parents, coping, education 
The Lived Experience of Fathers Whose Children are Diagnosed With a Genetic Disorder

"I felt something impossible for me to explain in words. Then, when they took her away, it hit me. I got scared all over again and began to feel giddy. Then it came to me ... I was a father" (Cole, n.d.). Fatherhood brings with it great emotion and responsibility. Add the reality of having a child diagnosed with a genetic disorder, and these emotions and responsibilities have the potential to become overwhelming.

"How would it make you feel if your daughter had something wrong with her and you knew it was your fault?" (C. Rivard, personal communication, April, 2010). For many parents of children with genetic disorders, this question is one wrought with misunderstanding, guilt, shame, and uncertainty (Hallowell et al., 2006; James, Hadley, Holtzman, \& Winkelstein, 2006). With a father's realization that a child's genetic anomaly will likely impact the life of his child and his family, comes an inevitable emotional response. However, past research has done little to gain an understanding of this reaction let alone help the father manage the repercussions of his child's disorder (Dellve, Samuelsson, Tallborn, Fasth, \& Hallberg, 2006; James, et al., 2006; Locock \& Alexander, 2006; May, 1996). Additional family expectations may enhance a father's reaction thereby compounding an already stressful situation. This stress has the potential to cause conflict in marital relationships (Sanders, Dittman, Keown, Farruggia, \& Rose, 2010).

Fathers' needs in circumstances where their child has been diagnosed with a genetic disorder have been largely overlooked by many in the healthcare professions. Conversely, the impact of a child's disease or disorder on mothers has been considered. This is largely due to the assumption that mothers have greater responsibility regarding 
child care (Mackey \& Goddard, 2006; Neff, 2010). Parental coping differences among those with children suffering from illness has also been reported (Pelchat, Lefebvre, \& Levert, 2007; Pelchat, Levert, \& Bourgeois-Guérin, 2009; Swallow, Lambert, Santacroce, \& Macfadyen, 2011). According to Pelchat, Levert, and Bourgeois-Guérin (2009), mothers and fathers generally respond to and cope with a child's illness from different perspectives and these differences have a direct impact on the family. For instance, because fathers tended to be outside the home more often than mothers, they had more opportunities to avoid problems associated with their child's disability whereas mothers utilized social networks and other services to deal with family and childcare issues. Mothers and fathers admitted to unequal division of tasks with the mother doing most of the work. Although fathers attempted to be helpful, their main contribution was as a support person for the mother. Negative responses such as tension and lack of communication were also reported (Pelchat, et al., 2009).

\section{Literature Review}

A significant problem was revealed during the review of literature; father's needs are not being met. Four general foci were identified related to this issue. First, father's reactions to childbirth and disability in their offspring differ from other family members (Dellve, et al., 2006; Lernmark et al., 2004; Pelchat, et al., 2007; Pelchat, et al., 2009; Ware \& Raval, 2007). Second, paternal stressors are generally related to financial issues, other family commitments, and feelings of incompetence surrounding the care of a child whether or not a disability exists (Barclay \& Lupton, 1999; Baum, 2004; Neil-Urban \& Jones, 2002). Third, a father's needs for education concerning the cause of disease, care of the child, and prognosis are not being adequately addressed (Barclay \& Lupton, 1999; 
Dellve, et al., 2006; Fletcher, Vimpani, Russell, \& Sibbritt, 2008; Lernmark, et al., 2004; Mackey \& Goddard, 2006). Fourth, paternal emotional responses, including stress and guilt, have a great impact on family function (Fletcher, et al., 2008; Pelchat, et al., 2007; Pelchat, et al., 2009; Ware \& Raval, 2007).

Research revealed that guilt can have a negative impact on personal and professional relationships and psychological well-being (Hallowell, et al., 2006; Lutwak, Panish, \& Ferrari, 2003; Tangney, Miller, Flicker, \& Barlow, 1996; Tilghman-Osborne, Cole, \& Felton, 2010). This negativity can lead to conflict in a father's relationships (Sanders, et al., 2010). According to Tangney, Miller, Flicker, and Barlow (1996) "when experiencing guilt, a person's focal concern is with a specific behavior or failure" (pp. 798). Fathers who feel responsible for their child's health, care, and welfare may feel that they have somehow misbehaved or failed to provide their child with components necessary to live a healthy and happy life.

Stress is a common reaction to the birth of a child. A father's desire to provide for his family's needs might add to this stress as he attempts to juggle personal and professional commitments while dealing with the changes associated with the growing family. Add the diagnosis of genetic anomaly in the child and the result was overpowering for some (Barclay \& Lupton, 1999; Baum, 2004; Hallowell, et al., 2006; Neil-Urban \& Jones, 2002). The increased demands placed on parents of children with genetic anomalies involved learning about the disorder as well as coping with the care, associated behaviors, and reorganization of their lives to provide for the needs of the child while maintaining other relationships (Dellve, et al., 2006). The unpredicatable nature of many genetic disorders had the potential to escalate parental stress (Pelchat, et 
al., 2009). According to Dellve, et al. (2006) fathers felt stress related to the perception of incompetence in dealing with and caring for the child. Pelchat et. al. (2009) stated that fathers reduced some of their stress by discussing concerns and issues with others. Although stress can have a positive effect in certain situations, in circumstances where stress overwhelms coping abilities, it can greatly increase the likelihood that a father becomes unable to deal with his responsibilities (Sanders, et al., 2010). Chesler and Perry (2001) described marital discord as a result of the stress related to having a child who was ill. Although they were referring to children with cancer, similarities such as long term illness and life-threatening outcomes could make this research applicable to fathers of children with genetic disorders as well.

Education has the potential to decrease stress and improve coping, confidence, and parenting skills. Dellve et.al., (2006), used a family competence intervention to assist parents in understanding and coping with a child's illness and found, "fathers showed high stress related to incompetence, which decreased after the intervention" (p. 392). When fathers were presented with information regarding their child's condition, a transformation took place where patience and perseverance developed, confidence was gained, and parenting skills advanced to new and more complex levels (Pelchat, et al., 2009). Nurses are in a unique position to educate fathers of children with genetic anomalies. By increasing nurses' knowledge of genetics, the potential to increase paternal knowledge and health literacy through education is immense (Lashley, 2001).

There is a lack of research related to issues that affect fathers when their child is diagnosed with a genetically transmitted anomaly. Parental guilt and stress are problems 
associated with disease and disorder in children. Fathers' responses to having a child with a genetic disorder have not been examined sufficiently.

\section{Method and Design}

Interpretive phenomenologic analysis (IPA) was utilized for this study because the research sought to understand a father's experience of discovering his child has a genetic disorder. IPA as described by Smith, Flowers, and Larkin (2009), is "concerned with the detailed examination of human lived experience . . . it aims to conduct this examination in a way which ... enables that experience to be expressed in its own terms, rather than according to predefined category systems" (p.32). Using IPA allows the researcher to develop "rich textual descriptions" as a means to make sense of behavior (Gillis \& Jackson, 2002).

\section{Sample}

Following institutional review board approval, participants were recruited with the assistance of nurses, physicians, and genetic counselors. Snowball sampling, internet and email recruitment, and word of mouth were also utilized. Participant recruitment took place from April until October, 2012. The final sample consisted of six fathers of children diagnosed with genetic disorders. All participants were married and had one to eight other children. See Table 1 for Demographics. Eligibility criteria included: (a) biological father of a child with a genetic disorder, (b) unaffected by the same genetic disorder as the child, (c) 18 years of age or older, and (d) able to speak, read, and write English. 


\section{Data Collection}

After providing written informed consent, participants were interviewed in person or via phone. Interviews were semi-structured using an interview guide, audio recorded, and transcribed verbatim. Identifying information was removed. Length of interviews ranged from 30-60 minutes. Participants were asked to describe their experience of having a child diagnosed with a genetic disorder. Additional questions were posed based on responses to previous questions and comments. Notes were taken describing verbal and nonverbal responses during questioning. All participants were asked about their educational experience with healthcare professionals as well as how the diagnosis affected their marital relationship.

\section{Data Analysis}

Data analysis was performed as described by Gillis and Jackson (2002) and began with reading and rereading transcripts throughout the data collection process. During data analysis, experiences were decontextualized. Decontextualization has been defined by Starks and Trinidad (2007) as separating information from its original context, then organizing, and coding the information into units of meaning. The resulting codes were then recontextualized. Recontextualization was defined as reflecting patterns, reintegration, and organization according to codes and finally, integration into data surrounding central themes. This process allowed for relationships within the data to be recognized (Portney \& Watkins, 2009; Starks \& Trinidad, 2007). Themes and commonalities or patterns assisted in identifying the structure of the phenomenon.

Trustworthiness of data was assessed according to Munhall (2007) who states, to be trustworthy four criteria must be met including, 1) credibility, 2) transferability, 3) 
dependability, and 4) confirmability. Credibility was assured via member checks and review by an expert in qualitative analysis. Transferability was met in that findings are expected to be applicable to others experiencing similar issues such as mothers or other providers who care for children with genetic disorders. An audit trail was utilized to provide dependability of the research so other researchers could reach similar conclusions in similar circumstances. The audit trail, member checks, and expert review assisted in development of confirmability by allowing for questioning of methods, accuracy, and meaningfulness of data (Gillis \& Jackson, 2002).

\section{Results}

The participant group consisted of six fathers whose children had been diagnosed with a genetic disorder. Children's diagnosis, time elapsed since diagnosis, prevalence, type of genetic disorder, and definition of disorder are included in Table 2, Diagnosis Information. Examination and interpretation of narratives revealed the existence of five themes: 1) the impact of diagnosis, 2) seeking understanding, 3) coping with effects of the disorder, 4) looking to the future, and 5) addressing a father's needs.

\section{The Impact of Diagnosis}

The impact of diagnosis varied little among participants. Most described feelings of shock, fear, devastation, and worry, while all revealed experiencing confusion at initial diagnosis. Recalling the emotional impact of diagnosis was obviously painful for the participants. Several of the men were noted to become hesitant and teary eyed during the conversations; many of their voices became shaky. For some fathers, their child experienced serious medical complications related to their genetic disorder at the time of diagnosis. This increased their fears and concerns. In all cases, confirmation of the 
genetic disorder required a minimum of 7-8 days and for some this occurred after the "newborn screening" results were returned.

The impact of diagnosis was greatly affected by the reaction of healthcare professionals when delivering the news of the child's disorder. All fathers reported a lack of knowledge among their initial healthcare professionals. One father said, "The first nurse we talked to pretty much said, your son is very, very, very sick and that's all that we could get out of them." Some dads also felt a lack of sensitivity among healthcare professionals. A father whose child has isovaleric acidemia (IVA) and was being treated for life-threatening complications, stated,

They printed off a sheet of about 4 or 5 sheets of paper and handed it to us and said this tells you about IVA and this is about all we know... Once they did get him stabilized they began to bring us, you know, all kinds of paperwork, all kinds of different things. . . They brought us a folder and they said you need to start looking at this stuff in the folder so you understand what's going on.

All of the participant's children were diagnosed with disorders considered "rare" in that they occur in less than 200,000 people in the United States (National Human Genome Research Institute, 2012). Because of the limited number of occurrences of these disorders, many of these men felt ill prepared for the diagnosis. They had little or no background knowledge about their child's condition. This lack of knowledge increased their feelings of fear and confusion because they had no foundation on which to base their expectations.

For three fathers, diagnosis did not occur until after complications related to the disorder developed. Because of the rarity of the disorders, there was a lack of knowledge, not just among the fathers, but also among healthcare professionals. The father's concerns were greatly heightened because some provider's knowledge was 
deficient regarding the signs, symptoms, treatment, and effects of each disorder. This lack of knowledge generally occurred at the initial treatment center they visited when their child became symptomatic. One father reported feeling "discouraged" by the insufficient knowledge among professionals he encountered stating "they were just as clueless as we were." Fathers reported feelings of confusion, discouragement, frustration, and shock during their child's illnesses following diagnosis, partly due to a shortage of information. One father remarked that once the diagnosis was known, "It was a relief to find out... that it was actually something that somebody knew about." This "relief" did not occur until days later, after transferring to a larger medical center with specialists more familiar with his child's condition.

Two fathers described different experiences with diagnosis in that their children's conditions were first suspected while in-utero. Following identification of anomalies in their fetuses, consultations with specialists resulted in the likely diagnosis of a genetic disorder. For one father, whose child had Down syndrome, the time of initial suspicion to the time of diagnosis took several weeks. He described the diagnosis as a "shock" but had been prepared for the possibility because his wife was a nurse who knew the likelihood of the diagnosis based on parental age and fetal anomalies identified on sonogram. For the other father, whose child was diagnosed with osteogenesis imperfecta, diagnosis was not confirmed until after the child had multiple broken bones during the first year of life. He described feeling "curiosity" because he was aware the condition was not life threatening. He also described confusion because specialists referred to the disorder in medical language rather than the more commonly known term, "brittle bone disease." 
Although these dads reported feelings of concern, fear, and shock for themselves, many also described concern for their wives. While dealing with the prospect of their child's disorder they worried how their wives would cope with the news and felt the need to provide comfort and support. In one case, the father stated "I was more concerned about my wife than I was about my (child at that point)." Due to the child's serious illness, concerns were expressed about whether the child would survive causing this dad to worry that his post-delivery wife would not be able to handle the stress and strain of the child's illness or death.

\section{Seeking Understanding}

Seeking understanding refers to the fathers' desire to obtain enough information to understand their child's condition as well as prepare for the child's future needs. Information sources included healthcare professionals and personal research. These factors and the effect of time on understanding are reported next.

Healthcare professionals. Each father stated that their initial contact at diagnosis was a physician, the primary source of information. In most cases, the dads described this first contact person as lacking knowledge about their child's disorder. This was especially true for those fathers whose children were diagnosed with "inborn errors of metabolism" and Prader-Willi syndrome (PWS) due to the extreme rarity of the conditions. This lack of knowledge among physicians led to inadequate education about important aspects of their child's health, resulting in feelings of fear and concern. One father stated,

The way it was described to us (by the physicians) is that they had briefly read about it while they were working (in) med school.... We met multiple, multiple doctors that (said my child) was the only occurrence that they had witnessed. 
Another father's initial contact appeared to be somewhat less disconcerting as he stated,

The doctor basically said the disorder is extremely rare and in his 25 years of practice, he'd never seen it once and he told us not to be freaked out by it . . . He was very comforting initially, before he really started talking about the symptoms.

One other dad stated, "They were surprised to find out (my child) had it and they, themselves, didn't seem to know a whole lot about it. I was recommended, pretty much, to just look it up online."

Most fathers recounted that the majority of information provided by the initial contacts consisted of papers printed from internet databases and websites specific to their child's disorder. According to one,

Even the lady who talked to us, who was their kind of metabolic contact, she said, "I've never seen this before and this is," she said, "all I can do for you is hand you this sheet of paper and it will tell you what we're talking about."

Following initial diagnosis, all of the participant's children were referred to larger healthcare centers outside their immediate area of residence. Time from initial diagnosis to consultation with specialists in these centers varied from several hours to several weeks depending on the child's condition. For most, this consultation meant a 1-2 hour drive. Once able to speak with specialists in these larger medical centers, each father felt he was presented with more in-depth explanation of his child's disorder as well as more reliable information concerning the child's condition and health outlook.

Fathers also had contact with genetic counselors once they reached the larger medical centers. Each dad found this group of professionals to be very helpful in teaching them about their child's condition as well as advising them regarding the probability of having another child with the same disorder. Along with consultation with 
genetic counselors, the fathers of children with inborn errors of metabolism and Prader-

Willi syndrome also had contact with nutritionists who were found to be a great resource in dealing with the nutritional issues of these disorders.

Nurses were also mentioned as sources of information as one father stated,

The nurses... didn't provide as much information specific to (my child's) disorder just because it is so specific. They provided a whole lot of information about okay, your child's going to have specific needs .... Your child has a g-tube, here are some things we've seen that really help with kids with g-tubes. Here are things we've really seen that help with kids with feeding issues. So, I mean, the nurses they were full of that kind of information. You know, he's got a little rash over here, this is just typical kid stuff. Here's what you can do to help with that.

Personal research. When healthcare professionals were unable to provide adequate information about their child's conditions, these fathers gathered their own materials to assist them in understanding the diagnosis. In some instances, they sought knowledge from family and friends. The father whose child was diagnosed with osteogenesis imperfecta stated, "A friend of my wife's actually had OI. We called her ... just to see what struggles and things that she had in her life, so we just educated ourselves." The dads also felt they became adept at internet research. Most were able to locate websites specific to their child's disorder as well as support groups and forums where they could communicate with others experiencing similar issues. This ability to locate information seemed to bring out a sense of accomplishment although fathers seemed agitated because they had to locate the material on their own. As one father confidently stated, "I feel fairly versed. Not to a molecular level of science and healthcare, but I feel pretty versed in what's going on and how it all happened. And so, I feel educated now I guess is what I could say." 
When their children were first diagnosed, most fathers felt overwhelmed by their own the lack of knowledge. The results, in many cases, were feelings of fear and confusion about their child's health and future. With time however, these men were able to overcome those feelings by locating knowledgeable healthcare providers and other information sources. The education, whether provided by healthcare professionals or found independently, provided these dads with greater knowledge enabling them to be more comfortable dealing with the ramifications of their child's disorder. One father commented, "It still scares me but I know how to live with it."

Effect of time. When participants were asked how they feel about their child's diagnosis now, after time allowed them to assimilate the information, all the men indicated that they realize these genetic disorders are not something they could have foreseen. The dads were vigilant about checking into their family histories to determine whether the disorders could be linked to family members. None of the fathers found a definitive link in their family history. In the cases where the disorder was passed on from the parents, the fathers appeared comfortable in their knowledge that they were not at fault for causing the condition. Three fathers used exactly the same words, "It is what it is." These dads understood how the disorders were passed to their children but most felt no guilt due to this knowledge. Only two fathers acknowledged feelings of guilt because their child's condition. In one case the feeling was related to the knowledge that the disorder was the result of a deletion of genetic material on the father's sperm. Although he admitted to feeling guilt, he was quick to qualify the remark by saying,

It was nice to know what caused it but also, at the same time, it basically was telling me that yes, it was my fault. But, they tried very hard to let me know, it's not like I could have done it on purpose. 
The other father, when asked about his feelings, knowing how the disorder was transmitted (autosomal recessive), laughingly stated, "I think the guilt kind of. . . I didn't have a problem with it. I mean it's not my fault it's my mom and dad's fault, they gave it to me."

\section{Coping with Effects of the Disorder}

Once participants developed an understanding of their child's disorder, the next step was to cope with the effects. This entailed maintaining the marital relationship, adjustment to caring for the child's special needs, and advocating for and teaching others about the condition.

Maintaining the marital relationship. The fathers in this study were all married to the mother of the child at the time of diagnosis and remain married to this day. When asked about changes in their relationships with their wives, these men either described becoming closer or having no change as a result of their child's genetic disorder. None acknowledged that the stress of the disorder and/or raising a child with special needs had a detrimental effect on the relationship. However, many took care to choose their words cautiously when describing the effect of diagnosis on their relationships which might have been an attempt to avoid the appearance of discord in the marriage.

For four fathers, diagnosis came soon after the birth of their child. These men described feelings of greater concern for their wives' welfare rather than their own or their child's. One father stated, "I was more concerned about my wife than I was about my son at this point. You know, how is my wife going to handle this?" Another said,

I just hugged her. I said, well now we know. . . You know I was trying to get through all the distractions and then you worry about my wife you know ... I'm making sure she's getting enough rest she's getting enough to eat. 
One dad mentioned an issue pertaining to his relationship with his wife stating that the lone concern for their future and relationship was the issue of having more children. He described, in a shaky voice,

We've begun discussions of, well, we would like for (our child) to have a sibling, you know, we both want, but I think we're both leery because it was hard. . . . You're tired and stressed so it's affected us there, to expand our family or not. We don't know yet.

Another father mentioned this thought while their child was hospitalized with serious complications of the disorder, "I understand that God's going to take care of things here but I don't know what I'm going to do with my wife if (our child) dies."

Adjustment to caring for the child's special needs. In each situation, learning to care for their child's special needs was a necessity. Each disorder has unique effects and must be dealt with accordingly. For the fathers this meant adjusting everyday life to include provision of care for their child.

In some cases, such as the child with galactosemia, the adjustment was felt by the father to be relatively simple as he stated, “(My child) can't have dairy milk. That was the only real change we needed to make that I was aware of." In other cases, multiple adjustments were necessary. The father whose child was diagnosed with PWS stated, "Chances are, that with that syndrome, they'll never be on their own, they can't be." The father whose child was diagnosed with VCLAD made this remark regarding his child's special needs, “ . . you're so tired. I mean, we still wake up every night with (our child), you feel like a zombie."

For two of the couples, adjusting to meet the needs of their child meant adapting the family situation so mom would not have to work. This adaptation allowed both 
parents to meet the needs of their child while maintaining the family relationship and reducing the stress of finding appropriate care.

Advocating for and teaching others about the child's condition. Because of the rare nature of these genetic disorders, the participants not only need to care for the child's needs themselves but also act as advocate to ensure the child is getting appropriate care elsewhere. For example, when one father's child is hospitalized, he acknowledged feeling this way about his role after finding errors in his child's unique care needs:

We're real leery, we don't trust doctors, we don't trust nurses. ... I think we've probably gotten that way just because they're not as well-versed on (our child's) condition.... There's a metabolic team, there's a head ER guy, and then there's whoever the attending is and then the nurses, so we've learned that we don't call the shots. The doctors obviously have all the control or whatever, but we have learned to be active choreographers in all of the events.

One father stated, "A lot of people think well, when is (my child) going to grow out of having IVA and that's not possible," so he felt it necessary to educate those who do not understand the disorder.

\section{Looking to the Future}

Once the initial shock of diagnosis ended and their child established more stable homeostasis, these fathers were able to start contemplating the future of their child's health and life as well as their own. The foci then became, what to expect, reaching out to others for support, and uncertainty about having more children.

What to expect. These fathers still had questions about their children's futures. Although some found or have been provided with information, many concerns remain. The dad whose child had PWS pointed out that understanding what to expect was helpful only up to a certain point: 
I found out the kind of things that you could expect them to have, their average IQ, different kinds of treatments and medications you could find, how you expect them to develop as far as mentally, physically, and all that stuff ... The scariest thing I probably found out is that it's way too easy for one of them to kill themselves (from overeating)... I can read (information) all I want but to really understand it I'm going to have to live it. I can't just read other people's accounts. I mean each one of them is different. You never know how they'll develop.

Most of these fathers felt similarly remarking that they would seek out and learn information as it became available and/or necessary as their child grows.

Reaching out to others for support. For many dads, seeking support from others has become a welcome technique for coping. Support was received from several sources including internet support groups and forums, family, friends, and healthcare professionals. The OI dad remarked,

(My wife's) family has been very supportive.... Her mom stayed here for two months, and her aunt stayed here for, I think, three weeks to help her because ... we just had our second child ... it was two weeks after (the new baby) was born, (my other child) broke his femur. Having a two-week-old and, at the time, a 16 (month old), you know, with a broken femur, it was a lot to handle ... so we had a lot of family support come down.

Many of these fathers commented on the importance of this support in helping them understand, work through, and deal with their child's condition.

Uncertainty about having more children. With genetic conditions, frequently, the question of having more children can be filled with uncertainty. This was a question that concerned many of the participants following diagnosis. At the time of interviews, five of the six dads had gone on to have additional children. They understood the risk but felt the chance of having another child with the disorder was minimal or not an issue. The sixth father did voice concern about the risk of having another child with the same condition. For this man, the main issue was having the energy to cope with another child 
considering the effort necessary for care of the child with the genetic disorder. He commented,

It was hard you know, I've talked with the families on Facebook and email and stuff and some of them act like (having another child) is no big deal. And I don't know if they're just cavalier in their outlook or what, but the thought of going through that, just the stress and you're so tired.

\section{Addressing a Father's Needs}

Meeting the unique needs of fathers whose children have genetic disorders requires an understanding of those needs. Issues of work interference and need for support as an integral part of the family unit were of great importance.

Work interference. The majority of participants indicated they would prefer to have more flexibility in their jobs to allow them to participate in childcare. They also felt increased flexibility would allow them to be more involved with medical appointments and treatment. One father stated,

I want to go to everything, especially with blood draws. I don't like it either . . it's better now because we're both accustomed to it, and (our child) pitifully so, has become more accustomed to it. (Our child) still doesn't like it. . . . You wouldn't get (my wife) to give up that baby until it was time for blood draw. Then all of a sudden she would hand it to me. (Laughing). Here's (the baby), it's time to share now. So yeah that was always my role. I didn't like it, but I had to suck it up and you know, I'd hold (our child) and we'd get through it. So if I knew that they were going to the doctor, if it was just to check up and they were just looking at her and talking to my wife or whatever, I'd still want to be there but I wouldn't feel bad. But if I knew there was any blood work or anything like that then yeah, I felt like I was, I guess, basically just letting them down not being able to be there.

Another dad stated, "I would rather stay home every day all day and help but I just can't do that to survive." Yet another father sadly revealed that he had not been able to attend any appointments with his child for over a year. 
Supporting dad. In most cases, fathers described feeling they were not the focus of educational efforts regarding their child's diagnosis and care although one described being addressed as parents rather than concentration being on mom or dad. Many participants described feeling "left out," because everyone focused on the wife. One dad stated mom had "more pull" with the healthcare professionals they encountered. The father whose child was diagnosed with Down syndrome commented,

Well I don't know that they necessarily cared about me that much. I think that they were more concerned ... about my wife because she was the one that was carrying the child and having to deal with the issues. You know, they let me know what was basically going on but I was kind of odd man out.

While several of these men appeared to believe the focus on mom was the result of expectations that she would provide the majority of care, they were not pleased with the assumption and the lack of inclusion.

One father felt exclusion not only from the healthcare professionals he encountered but also from his wife. He stated,

I kind of wish from the beginning I'd felt like I was actually included in everything. I first felt like I was left out by the doctors giving us the information. ... I feel like (my wife has) basically taken charge of the situation and I'm being left behind.... I'm just a spectator in the whole thing.

While most of the participants expressed discontent at the focus on maternal needs, one father had the opposite experience where physicians focused dialogue on him rather than his wife or the two as a couple. He criticized this practice feeling that the male physicians tended to address him because he was male. This father added that he felt obligated to ask his wife if she had questions or concerns because the physicians they encountered did not address her needs or inquiries. 


\section{Limitations}

There are several study limitations including the small sample size. Although recruitment took place over a six month period, only six fathers agreed to participate. The use of phone interviews for two participants allowed for the inclusion of fathers from other areas of the country; however, it might have reduced the richness of the interviews due to the absence of visual observation. In addition, the sample population was culturally homogenous. All fathers were Caucasian, college educated, worked 40 or more hours per week, and were married and, as a result, findings cannot be generalized to other groups.

\section{Discussion and Recommendations}

The impact of having a child diagnosed with a genetic disorder was profound. Being a father to a child with a genetic anomaly brought unique and exceptional issues of concern. In the past, little attention was given to addressing a father's distinctive perspective and needs related to the understanding of his child's diagnosis and care as well as health and life outlook. To properly prepare these dads to cope with this major life change, it is important to provide for the basic necessities required to meet his needs.

The impact of diagnosis could be greatly improved by providing these dads with information from the beginning. The fathers all recalled professionals who lacked knowledge and sensitivity. Some described a lackadaisical attitude from professionals.

For several of the participants, what was expected to be a normal birth experience, ended in neonatal complications related to their child's undiagnosed disorder. These complications added to the distress brought on by diagnosis. To remedy this situation, protocols are needed that insure healthcare professionals remember the parent's 
emotional responses in the midst of turmoil. Assigning a specific person to interact with the parents and locate and explain information could be useful in alleviating some of their fears. It is also important to ensure that both parents are included in the conversation. Taking care not to focus on an individual parent is imperative in helping both to feel part of the childcare team.

The issue of time to confirm the diagnosis might have also had an effect on the father's reactions. In several cases, the child developed complications related to the genetic disorder but the presence of the condition was not known or confirmed for several days to weeks. As reported by Skirton (2006), waiting for results of testing is "one of the worst stressors for parents" (p. 178).

Fathers frequently felt devalued when conversation focused on the mother. When a child has an illness or disability, they often felt excluded, ignored, and marginalized by the healthcare community. Fathers have an intense desire to be involved in their child's care and addressing his needs will assist him in transitioning to his role as father and coping with the news of diagnosis (May, 1996; O'Leary \& Thorwick, 2006; Perry, et al., 2010).

Emotional support at the time of diagnosis and beyond is imperative for fathers. Although the literature suggested that guilt could be an issue for these fathers, most of the men did not describe this emotion. In some cases however, body language and voice inflection indicated feelings that were not acknowledged during the interviews. When providing emotional support, healthcare providers should be aware of fathers' verbal and nonverbal cues because they will frequently attempt to hide their feelings due to fear of losing control, or being seen as ineffectual or weak (Perry, et al., 2010). 
According to Perry, et. al. (2010), parents will often experience grief as a result of the loss of what was imagined, planned, or hoped for when a child is diagnosed with an anomaly. The sense of loss can result in crisis for parents. Fathers in this study made no reference to feelings of loss or grief related to their child's diagnosis. This may have been due to interview questions not being specifically designed to address this issue and/or because men may avoid discussion of their emotional reactions (Perry et. al., 2010). Although participants did not indicate feeling a sense of loss or grief related to their child's disorder, nurses and other healthcare providers need to be aware of this potential response and provide care accordingly.

Providers need to be diligent in their observations of every aspect of a father's reaction to ensure that all facets of emotional well-being are addressed. Failing to address a father's needs can result in increased stress, depression, guilt, powerlessness, isolation, embarrassment, and anger. Anticipatory guidance, emotional support, assistance with stressor identification and development of coping mechanisms, and problem solving strategies can help dads to feel empowered and better able to manage their own needs as well as those of their child (Perry, et al., 2010).

Contrary to the literature, for this group of fathers marital relationships were not detrimentally affected by the diagnosis of their child. Each couple managed to maintain their relationship without allowing the stresses of their child's disorder become a barrier to communication and caring. Follow-up examination of these relationships over time might prove to be valuable in identification of whether alterations in relationships occur as the child ages, consequences of their disorders change, and long-term stress becomes an issue. 
Education of these fathers should be a priority in provision of family-centered care. This group of dads felt let-down by many in the healthcare profession because their expectation was that professionals would provide the information necessary to help them understand their child's diagnosis. The main issue seemed to be a knowledge deficit among healthcare professionals. Because the majority of genetic disorders are considered "rare," the lack of experience with the children's conditions and lack of professional education about what the conditions involved led to a shortfall of information for the parents. Therefore, enhanced education regarding genetic transmission and disorders should be a priority for healthcare professionals and patient/family educators. Development of a detailed knowledge base for genetic disorders could be of great use in helping healthcare professionals provide accurate patient and family teaching.

Educators must also be aware of the changing climate in genetic and genomic research. Keeping nurses and other healthcare providers up to date on changes and advances in the science should be a priority. Knowledge of these changes and advances can then be passed on to patients and families, helping them to remain knowledgeable and increasing their comfort and competence in providing and receiving care (Guttmacher, Porteous, \& McInerney, 2007). Future research should assess nursing curriculum and continuing education programs related to genetics and genomics and update according to current knowledge. A qualitative study regarding nurses' view of their role in educating patients, families, and themselves could also prove useful.

Keeping fathers involved is essential to helping a father cope with his child's disorder. As nurses, it is important to remember that frequently fathers are the sole source or major source of family income. Families with children who have special needs 
such as those associated with many genetic disorders, often have additional medical costs. These issues can lead to financial difficulty for the family. Because of to the need to maintain adequate income, fathers are oftentimes not able to be involved in their child's care to the extent they desire. Juggling the demands of work and family can have a detrimental effect on fathers and their families (Barclay \& Lupton, 1999; Baum, 2004; Neil-Urban \& Jones, 2002). Engagement would help dad feel a part of the family and healthcare team as well as important in maintaining his child's wellbeing. Fathers should not be left to feel they are "sitting on the sidelines" when it comes to their child's care. Implementation of flexible office hours and appointments might be a great tool for increasing paternal involvement.

\section{Conclusion}

Traditional parental roles suggest that mothers are responsible for the care and nurturing of children thus, fathers are frequently forgotten in the midst of conversations about children born with genetic anomalies. Fathers need to understand the diagnosis, have unique coping abilities, and distinctive needs, thus nurses must intervene to improve outcomes for them and their families. Nurses, as an integral part of the healthcare team, should be instrumental in ensuring that fathers are included and their needs are met. Being mindful of a father's unique needs must be an integral part of the healthcare plan because his role, although different from the mother's, is an important part of providing for a child's well-being. 


\section{References}

Barclay, L., \& Lupton, D. (1999). The experiences of new fatherhood: A socio-cultural analysis. Journal of Advanced Nursing, 29(4), 1013-1020. doi: 10.1046/j.13652648.1999.00978.x

Baum, L. S. (2004). Internet parent support groups for primary care givers of a child with special health care needs. [Support for Parents of Children with Special Health Care Needs: Continuing Education Series.]. Pediatric Nursing September/October, 30(5), 381-388.

Chesler, M. A., \& Parry, C. (2001). Gender roles and/or styles in crisis: an integrative analysis of the experiences of fathers of children with cancer. Qualitative Health Research, 11(3), 363-384.

Cole, N. K. (n.d.). Fatherhood Quotations http://quotations.about.com/od/specialdays/a/fatherhood_life.htm

Dellve, L., Samuelsson, L., Tallborn, A., Fasth, A., \& Hallberg, L. R. (2006). Stress and well-being among parents of children with rare diseases: A prospective intervention study. Journal of Advanced Nursing, 53(4), 392-402. doi: 10.1111/j.1365-2648.2006.03736.x

Fletcher, R., Vimpani, G., Russell, G., \& Sibbritt, D. (2008). Psychosocial assessment of expectant fathers. Archives of Women's Mental Health, 11(1), 27-32. doi: 10.1007/s00737-008-0211-6

Gillis, A., \& Jackson, W. (2002). Research for nurses; Methods and interpretation. Philadelphia: F. A. Davis.

Guttmacher, A. E., Porteous, M. E., \& McInerney, J. D. (2007). Educating health-care professionals about genetics and genomics. [Article]. Nature Reviews Genetics, 8(2), 151-157. doi: 10.1038/nrg2007

Hallowell, N., Arden-Jones, A., Eeles, R., Foster, C., Lucassen, A., Moynihan, C., \& Watson, M. (2006). Guilt, blame and responsibility: Men's understanding of their role in the transmission of BRCA1/2 mutations within their family. Sociology of Health \& Illness, 28(7), 969-988. doi: 10.1111/j. 14679566.2006.00515.x 
James, C. A., Hadley, D. W., Holtzman, N. A., \& Winkelstein, J. A. (2006). How does the mode of inheritance of a genetic condition influence families? A study of guilt, blame, stigma, and understanding of inheritance and reproductive risks in families with X-linked and autosomal recessive diseases. Genetics In Medicine: Official Journal Of The American College Of Medical Genetics, 8(4), 234-242. doi: 10.1097/01.gim.0000215177.28010 .6e

Lashley, F. (2001). Genetics and nursing: The interface in education, research, and practice. Biological Research For Nursing, 3(13), 13-23. doi: 10.1177/109980040100300103

Lernmark, B., Elding-Larsson, H., Hansson, G., Lindberg, B., Lynch, K., \& Sjöblad, S. (2004). Parent responses to participation in genetic screening for diabetes risk. Pediatric Diabetes, 5(4), 174-181. doi: 10.1111/j. 1399-543X.2004.00070.x

Leslie, N., Tinkle, B., Strauss, A., Shooner, K., \& Zhang, K. (2011). Very Long-Chain Acyl-Coenzyme A Dehydrogenase Deficiency. GeneReviews. Retrieved from http://www.ncbi.nlm.nih.gov/books/NBK6816/

Locock, L., \& Alexander, J. (2006). 'Just a bystander'? Men's place in the process of fetal screening and diagnosis. Social Science \& Medicine, 62(6), 1349-1359. doi: 10.1016/j.socscimed.2005.08.011

Lutwak, N., Panish, J., \& Ferrari, J. (2003). Shame and guilt: Characterological vs. behavioral self-blame and their relationship to fear of intimacy. [Article].

Personality \& Individual Differences, 35(4), 909. doi: 10.1016/s01918869(02)00307-0

Mackey, S., \& Goddard, L. D. (2006). Promoting the health of families of children with disabilities: Acceptability and utility of a health-mentoring project. Diversity in Health \& Social Care, 3(2), 141-149.

May, J. (1996). Family matters. Fathers: the forgotten parent. Pediatric Nursing, 22(3), 243.

Munhall, P. (2007). Nursing research: A qualitative perspective (4th ed.). Boston: Jones and Bartlett.

National Human Genome Research Institute. (2012, February 27). What is a rare disease? Retrieved October 5, 2012, from http://www.genome.gov/27531963 
Neff, P. E. (2010). Fathering an ADHD child: An examination of paternal well-being and social support. Sociological Inquiry, 80(4), 531-553. doi: 10.1111/j.1475682X.2010.00348.x

Neil-Urban, S., \& Jones, J. B. (2002). Father-to-father support: Fathers of children with cancer share their experience. Journal of Pediatric Oncology Nursing, 19(3), $97-$ 103. doi: $10.1177 / 104345420201900304$

O'Leary, J., \& Thorwick, C. (2006). Fathers' perspectives during pregnancy, postperinatal loss. JOGNN: Journal of Obstetric, Gynecologic \& Neonatal Nursing, 35(1), 78-86. doi: 10.1111/j.1552-6909.2006.00017.x

Pelchat, D., Lefebvre, H., \& Levert, M. (2007). Gender differences and simililarities [sic] in the experience of parenting a child with a health problem: current state of knowledge. Journal of Child Health Care, 11(2), 112-131. doi: $10.1177 / 1367493507076064$

Pelchat, D., Levert, M., \& Bourgeois-Guérin, V. (2009). How do mothers and fathers who have a child with a disability describe their adaptation/transformation process? Journal of Child Health Care, 13(3), 239-259. doi: $10.1177 / 1367493509336684$

Perry, S., Hockenberry, M., Lowdermilk, D., \& Wilson, D. (2010). Maternal child nursing care. Maryland Heights: Mosby.

Portney, L., \& Watkins, M. (2009). Foundations of clinical research, applications to practice (3rd ed.). Upper Saddle River: Pearson Education Inc.

Sanders, M. R., Dittman, C. K., Keown, L. J., Farruggia, S., \& Rose, D. (2010). What are the parenting experiences of fathers? The use of household survey data to inform decisions about the delivery of evidence-based parenting interventions to fathers. Child Psychiatry \& Human Development, 41(5), 562-581. doi: 10.1007/s10578-010-0188-z

Skirton, H. (2006). Parental experience of a pediatric genetic referral. MCN: The American Journal of Maternal Child Nursing, 31(3), 178-184.

Smith, J. A., Flowers, P., \& Larkin, M. (2009). Interpretive phenomenologic analysis: Theory, method and research. Los Angeles: Sage. 
Starks, H., \& Trinidad, S. (2007). Choose your method: A comparison of phenomenology, discourse analysis, and grounded theory. Qualitative Health Research, 17(10), 1372-1380. doi: 10.1177/1049732307307031

Swallow, V., Lambert, H., Santacroce, S., \& Macfadyen, A. (2011). Fathers and mothers developing skills in managing children's long-term medical conditions: How do their qualitative accounts compare? Child Care Health and Development, 37(4), 512-523. doi: 10.1111/j.1365-2214.2011.01219.x

Tangney, J. P., Miller, R. S., Flicker, L., \& Barlow, D. H. (1996). Are shame, guilt, and embarrassment distinct emotions? Journal of Personality and Social Psychology, 70(6), 1256-1269. doi: 10.1037/0022-3514.70.6.1256

Tilghman-Osborne, C., Cole, D. A., \& Felton, J. W. (2010). Definition and measurement of guilt: Implications for clinical research and practice. Clinical Psychology Review, 30(5), 536-546. doi: 10.1016/j.cpr.2010.03.007

U.S. National Library of Medicine. (2007a). Isovaleric Acidemia, Retrieved October 6, 2012, from http://ghr.nlm.nih.gov/condition/isovaleric-acidemia

U.S. National Library of Medicine. (2007b). Osteogenesis imperfecta Retrieved October 16, 2012, from http://ghr.nlm.nih.gov/condition/osteogenesis-imperfecta

U.S. National Library of Medicine. (2008). Galactosemia, Retrieved October 6, 2012, from http://ghr.nlm.nih.gov/condition/galactosemia

U.S. National Library of Medicine. (2009). Very long-chain acyl-CoA dehydrogenase deficiency, Retrieved October 6, 2012, from http://ghr.nlm.nih.gov/condition/very-long-chain-acyl-coa-dehydrogenasedeficiency

U.S. National Library of Medicine. (2011). Prader-Willi Syndrome, Retrieved October 6, 2012, from http://ghr.nlm.nih.gov/condition/prader-willi-syndrome

U.S. National Library of Medicine. (2012). Down syndrome, Retrieved October 6, 2012, from http://ghr.nlm.nih.gov/condition/down-syndrome 
Ware, J., \& Raval, H. (2007). A qualitative investigation of fathers' experiences of looking after a child with a life-limited illness, in process and in retrospect. Clinical Child Psychology \& Psychiatry, 12(4), 549-565. doi: 10.1177/1359104507080981 
Table 1

Demographics

\begin{tabular}{cl}
\hline & $\begin{array}{l}\text { Number of } \\
\text { Participants }\end{array}$ \\
\hline Age Range & 3 \\
$21-29$ & 2 \\
$30-39$ & 1 \\
$50-59$ & \\
Education & 2 \\
Associate's Degree & 3 \\
Bachelor's Degree & 3 \\
Graduate Degree & 1 \\
Employment Status & \\
Employed 40 or & \\
more/week & 6 \\
Race $\quad$ & 6 \\
White & \\
Marital Status & 6 \\
Married & 1 \\
Income & 2 \\
$20 \mathrm{~K}-34,000$ & \\
$35 \mathrm{~K}-49,999$ & \\
$50 \mathrm{~K}-74,999$ & 1 \\
$75 \mathrm{~K}-149,999$ & 2
\end{tabular}




\section{Table 2}

\section{Diagnosis Information}

\begin{tabular}{|c|c|c|c|c|c|}
\hline $\begin{array}{l}\text { Participant } \\
\text { Number }\end{array}$ & $\begin{array}{l}\text { Time since } \\
\text { Diagnosis }\end{array}$ & Diagnosis & Prevalence & $\begin{array}{l}\text { Type Of Genetic } \\
\text { Disorder }\end{array}$ & Definition \\
\hline 0001 & 15 months & Galactosemia & $\begin{array}{c}\text { Classic } \\
\text { galactosemia: } 1 \text { in } \\
30,000 \text { to } 60,000 ; \\
\text { Duarte variant: } \\
\text { unknown } \\
\text { (U.S. National } \\
\text { Library of } \\
\text { Medicine, 2008) }\end{array}$ & $\begin{array}{l}\text { Autosomal } \\
\text { recessive: Duarte } \\
\text { variant }\end{array}$ & $\begin{array}{l}\text { "A disorder that affects how the } \\
\text { body processes a simple sugar } \\
\text { called galactose ... Affect(s) } \\
\text { different enzymes involved in } \\
\text { breaking down galactose ... The } \\
\text { Duarte variant reduces but does } \\
\text { not eliminate the activity of the } \\
\text { enzyme... Infants typically } \\
\text { develop feeding difficulties, } \\
\text { (lethargy, failure to thrive, } \\
\text { jaundice), liver damage, and } \\
\text { bleeding." (U.S. National Library } \\
\text { of Medicine, 2008) }\end{array}$ \\
\hline 0002 & 3.5 years & $\begin{array}{c}\text { Prader-Willi } \\
\text { syndrome (PWS) }\end{array}$ & $\begin{array}{l}1 \text { in } 10,000 \text { to } \\
30,000 \text { people } \\
\text { worldwide } \\
\text { (U.S. National } \\
\text { Library of } \\
\text { Medicine, 2011) }\end{array}$ & $\begin{array}{l}\text { Partial deletion } \\
\text { chromosome } 15\end{array}$ & $\begin{array}{l}\text { "A complex genetic condition } \\
\text { that affects many parts of the } \\
\text { body. In infancy ... } \\
\text { characterized by (hypotonia), } \\
\text { feeding difficulties, poor growth, } \\
\text { and delayed development... In } \\
\text { childhood, (they) develop an } \\
\text { insatiable appetite, (leading to } \\
\text { hyperphagia) and obesity." (U.S. } \\
\text { National Library of Medicine, } \\
\text { 2011). }\end{array}$ \\
\hline p003 & 2 years & $\begin{array}{c}\text { Isovaleric acidemia } \\
\text { (IVA) }\end{array}$ & $\begin{array}{c}1 \text { in } 250,000 \text { people } \\
\text { in the United States } \\
\text { (U.S. National } \\
\text { Library of Medicine, } \\
2007 \text { a) }\end{array}$ & $\begin{array}{l}\text { Autosomal } \\
\text { recessive }\end{array}$ & $\begin{array}{l}\text { "A rare disorder in which the body } \\
\text { is unable to process certain } \\
\text { proteins properly. It is classified } \\
\text { as an organic acid disorder, which } \\
\text { is a condition that leads to an } \\
\text { abnormal buildup of particular } \\
\text { acids known as organic acids. } \\
\text { Abnormal levels of organic acids } \\
\text { in the blood (organic acidemia), } \\
\text { urine (organic aciduria), and } \\
\text { tissues can be toxic and can cause } \\
\text { serious health problems." (U.S. } \\
\text { National Library of Medicine, } \\
\text { 2007a) }\end{array}$ \\
\hline 0004 & 3 years & $\begin{array}{c}\text { Very long-chain } \\
\text { acyl-CoA } \\
\text { dehydrogenase } \\
\text { deficiency (VCLAD) }\end{array}$ & $\begin{array}{l}1 \text { in } 40,000 \text { to } \\
120,000 \text { (U.S. } \\
\text { National Library of } \\
\text { Medicine, 2009) }\end{array}$ & $\begin{array}{l}\text { Autosomal } \\
\text { recessive: cardiac } \\
\text { variant }\end{array}$ & $\begin{array}{l}\text { "A condition that prevents the } \\
\text { body from converting certain fats } \\
\text { to energy, particularly during } \\
\text { periods without food" (U.S. } \\
\text { National Library of Medicine, } \\
\text { 2009). Cardiac involvement } \\
\text { "typically presents in the first } \\
\text { months of life with hypertrophic } \\
\text { or dilated cardiomyopathy, } \\
\text { pericardial effusion, and } \\
\text { arrhythmias." (Leslie, Tinkle, } \\
\text { Strauss, Shooner, \& Zhang, 2011) }\end{array}$ \\
\hline
\end{tabular}

\section{Continued on next page}


Table 2 continued

\begin{tabular}{|c|c|c|c|c|c|}
\hline $\begin{array}{l}\text { Participant } \\
\text { Number }\end{array}$ & $\begin{array}{l}\text { Time since } \\
\text { Diagnosis }\end{array}$ & Diagnosis & Prevalence & $\begin{array}{c}\text { Type Of Genetic } \\
\text { Disorder }\end{array}$ & Definition \\
\hline 0005 & 13 years & Down syndrome & $\begin{array}{l}1 \text { in } 700 \text { (U.S. } \\
\text { National Library of } \\
\text { Medicine, 2012) }\end{array}$ & $\begin{array}{l}\text { Nondisjunction, } \\
\text { trisomy } 21\end{array}$ & $\begin{array}{l}\text { "A chromosomal condition that is } \\
\text { associated with intellectual } \\
\text { disability, a characteristic facial } \\
\text { appearance, and (hypotonia) in } \\
\text { infancy. All affected individuals } \\
\text { experience cognitive delays, but } \\
\text { the intellectual disability is|usually } \\
\text { mild to moderate. People with } \\
\text { Down syndrome may have a } \\
\text { variety of birth defects." (U.S. } \\
\text { National Library of Medicine, } \\
\text { 2012) }\end{array}$ \\
\hline 0006 & 22 months & $\begin{array}{c}\text { Osteogenesis } \\
\text { imperfecta, type I }\end{array}$ & $\begin{array}{c}\text { All types: } 6 \text { to } 7 \text { per } \\
100,000 \text { people } \\
\text { worldwide; Type I: } 4 \\
\text { to } 5 \text { per } 100,000 \\
\text { people worldwide } \\
\text { (U.S. National Library } \\
\text { of Medicine, 2007b) }\end{array}$ & $\begin{array}{l}\text { Autosomal } \\
\text { dominant }\end{array}$ & $\begin{array}{l}\text { "A group of genetic disorders that } \\
\text { mainly affect the bones ... People } \\
\text { with this condition have bones that } \\
\text { break easily, often from mild } \\
\text { trauma or with no apparent cause. } \\
\text { Multiple fractures are common, } \\
\text { and in severe cases, can occur even } \\
\text { before birth. Milder cases may } \\
\text { involve only a few fractures over a } \\
\text { person's lifetime. . Type I is the } \\
\text { mildest form." (U.S. National } \\
\text { Library of Medicine, 2007b) }\end{array}$ \\
\hline
\end{tabular}




\section{Summary and Conclusion}

Patterns are evident in countless areas of the universe, from the smallest atomic particle to the configuration of galaxies. In nursing, patterns are seen in many forms including the structure of DNA, the beat of the heart, labor contractions, psychological responses, and human growth and development. When physical or psychological patterns become disrupted chaos often ensues, frequently resulting in disorder, illness, and death. The manuscript, Pattern, A Concept Analysis in the Context of Genetic Development and Evolution, provides useful information for understanding the process by which patterns and chaos interact. Recognition of patterns is essential to provide the population with high quality healthcare. By learning to recognize patterns and alterations that might lead to illness, nurses are in an inimitable position to create change and achieve a new way of thinking about health and illness (Topolski, 2009; Vicenzi, 1994). With further study and recognition of effective treatment, persons with genetic disorders may experience improved quality of life and eventually, a cure. Study of these patterns is essential to understanding their effects and creating successful preventative and/or treatment modalities.

To provide competent care to a father whose child is diagnosed with a genetic disorder, nurses and other healthcare professionals must understand his unique needs. As in many aspects of healthcare, patterns can be identified in the ways a father reacts to the diagnosis. In the document, The Lived Experience of Fathers Whose Children are Diagnosed with a Genetic Disorder, reaction patterns or themes were identified based on participant's responses to interview questions. These themes included: 1) the impact of 
diagnosis, 2) seeking understanding, 3) coping with effects of the disorder, 4) looking to the future, and 5) addressing a father's needs.

The small sample size of six is considered a weakness of this study although saturation was reached. Recruitment took place from April to October, 2012 with the assistance of nurses, physicians, and genetic counselors. Snowball sampling, internet and email recruitment, and word of mouth were also utilized. Another limitation was the lack of diversity in the sample. All participants were married, Caucasian, working 40 or more hours per week, and college educated. The study included some diversity in fathers ages, ranging from 20's to 50's, and types of genetic disorders in their children, with no diagnosis being repeated in another father's child.

Data analysis was performed as described by Gillis and Jackson (2002) and began with reading and rereading transcripts throughout the data collection process. During data analysis, experiences were decontextualized. The resulting codes were then recontextualized to integrate findings into central themes.

Trustworthiness of data was assessed according to Munhall (2007) who states, to be trustworthy four criteria must be met including, 1) credibility, 2) transferability, 3) dependability, and 4) confirmability. Credibility was assured via member checks and review by an expert in qualitative analysis. The concept of transferability was confirmed as the findings are expected to be applicable to others experiencing similar issues such as mothers or other providers who care for children with genetic disorders. An audit trail was utilized to provide dependability of the research. The audit trail, member checks, and expert review assisted in development of confirmability (Gillis \& Jackson, 2002). 
Addressing a father's unique needs when experiencing the diagnosis of genetic disorder in his child, offers distinctive challenges. Healthcare professionals must take care to avoid the perception that they are ignorant about the condition and lack of sensitivity when working with fathers experiencing the shock of diagnosis. Emotional support including anticipatory guidance, assistance with stressor identification and development of coping mechanisms, and problem solving strategies is a necessity (Perry, et al., 2010). Professionals should also attempt to adjust schedules and treatments to allow for inclusion of fathers in the child's treatment process.

Education must be a priority for theses dads. Educators, including nurses and physicians, must be aware of the changing climate in genetics and genomics. Keeping nurses and other healthcare providers up to date on changes and advances in the science should be a priority. Development of a detailed database for genetic disorders could be of great use in helping healthcare professionals provide accurate patient and family teaching.

Future research should include identification of areas in the nursing curriculum and continuing education related to genetics and genomics, specific topics in need of updating, as well as assessment of nurse's general knowledge in this area. A qualitative study regarding nurses' view of their role in educating patients, families, and themselves could also prove useful.

Fathers whose children are diagnosed with genetic disorders have unique needs. By understanding the impact of diagnosis on a father, his essential right and need to understand the diagnosis, his coping abilities, and distinctive needs, nurses and other 
healthcare professionals must develop interventions designed to improve outcomes for father's and their families. 


\section{References}

Gillis, A., \& Jackson, W. (2002). Research for nurses; Methods and interpretation. Philadelphia: F. A. Davis.

Munhall, P. (2007). Nursing research: A qualitative perspective (4th ed.). Boston: Jones and Bartlett.

Perry, S., Hockenberry, M., Lowdermilk, D., \& Wilson, D. (2010). Maternal child nursing care. Maryland Heights: Mosby.

Topolski, S. (2009). Understanding health from a complex systems perspective. Journal of Evaluation in Clinical Practice, 15(4), 749-754.

Vicenzi, A. E. (1994). Chaos theory and some nursing considerations. Nursing Science Quarterly, 7(1), 36-42. doi: 10.1177/089431849400700112 


\section{Appendix A}

\section{Detailed Research Procedure Protocol}

Before research activities commenced, approval for the study was obtained from The Institutional Review Board (IRB) at The University of Texas at Tyler (See Appendix B). Expedited approval was granted.

\section{Sample}

The target population included fathers of a child with a genetic anomaly. Participants were recruited from pediatric, obstetric, and genetic service offices in the North Central Texas and Oklahoma areas. Internet sites that provide information and support to families of children with genetic disorders, such as the National Down Syndrome Society and Prader-Willi Association, were also approached to assist in recruitment. Snowball sampling, email, and word of mouth were also used. These techniques were employed for recruitment of participants until data saturation was reached. The sample was one of convenience chosen on the basis of having met inclusion and exclusion criteria and availability during the period of time defined for the research study.

Inclusion criteria for this research include:

- Biologic father of a child with a genetic disorder.

- Father able to speak, read, and write the English language.

- Father available for interview and willing to share experiences

Exclusion criteria include:

- Fathers with the same genetic disorder as the child.

- Fathers under the age of 18. 


\section{Appendix A Continued}

\section{Data Collection Procedure}

In phenomenologic research the researcher acts as the instrument, engaging in analysis as a witness to the accounts described in the data (Starks \& Trinidad, 2007). In this study, the researcher became immersed in the data through interview and observation of behavior during the interview process as well as reading and examination of individual experiences obtained during discussion.

Data collection took place face-to-face or by phone. For one-on-one interviews, a meeting place was mutually agreed upon by the participant and investigator. Interviews were semi-structured in nature, audio recorded, and transcribed verbatim (see Appendix C for Interview Guide). Identifying information was removed. Length of interviews ranged from 30-60 minutes. The investigator provided a brief introduction, explained the purpose, procedure, and time requirements for the study, and offered the opportunity for participants to ask questions prior to beginning each interview. A demographic questionnaire was provided and completed prior to each interview (See Appendix D for demographic questionnaire). Interviews and data collection continued until saturation was reached. Participants were asked to describe their experience of having a child diagnosed with a genetic disorder. Additional questions were posed based on responses to previous questions and comments. Notes were taken describing verbal and nonverbal responses during questioning. All participants were asked about their educational experience with healthcare professionals as well as how the diagnosis affected their marital relationship. 


\section{Appendix A Continued \\ Data Management}

\section{Analysis}

Data analysis was performed as described by Gillis and Jackson (2002) and began with reading and rereading transcripts throughout the data collection process. During data analysis, experiences were decontextualized. Decontextualization was defined by Starks and Trinidad (2007) as separating information from its original context, then organizing, and coding the information into units of meaning. The resulting codes were then recontextualized. Recontextualization was defined as reflecting patterns, reintegration, and organization according to codes and finally, integration into data surrounding central themes. This process allowed for relationships within the data to be recognized (Portney \& Watkins, 2009; Starks \& Trinidad, 2007). These themes and commonalities or patterns assisted in identifying the structure of the phenomenon under investigation. Following identification of the structure, a comparison was made between the findings and the transcribed interviews to assure a fit between the themes and data. After analysis, member checks were performed to verify or clarify information. Interpretation of data was performed with consideration of the iterative, inductive nature of the phenomenologic method (Starks \& Trinidad, 2007).

\section{Trustworthiness}

According to Munhall (2007), trustworthiness is necessary for a quality qualitative study. To be trustworthy four criteria must be met including, 1) credibility, 2) transferability, 3) dependability, and 4) confirmability. 


\section{Appendix A Continued}

Credibility was assured with the use of member checks and review by an expert in qualitative analysis. Transferability was met in that findings are expected to be applicable to others experiencing similar issues such as mothers or other providers who care for children with genetic disorders. An audit trail was utilized to provide dependability of the research so other researchers could reach similar conclusions in similar circumstances. The audit trail, member checks, and expert review assisted in development of confirmability by allowing for questioning of methods, accuracy, and meaningfulness of data (Gillis \& Jackson, 2002Gillis \& Jackson, 2002). In addition, selfreflection through "bracketing" was utilized by the researcher as a means to recognize existing knowledge and assumptions so they could be put to the side. Bracketing assisted the investigator to have an "open mind" during analysis and decreased the risk of preconceived notions and prejudices affecting the research process (Munhall, 2007;

Starks \& Trinidad, 2007).

\section{Informed Consent}

Potential participants were provided a copy of the informed consent (Appendix E). Confidentiality was ensured by keeping consent forms in a secure, locked location in the researcher's home and identifying participants with a code number.

\section{Data Transcription}

Data transcription and entry into an electronic database was done by the researcher. This helped to insure the information was restricted to only those involved in the research process. 


\section{Appendix A Continued}

\section{Storage}

Data was stored at the investigator's home. All written and audio-taped materials were secured in a locked cabinet with the only key being in the researcher's possession. Transcribed interviews were stored on the investigator's personal computer and secured by password protection. A backup copy of the interviews was kept on a password protected flash drive and secured in a locked cabinet at the researcher's place of employment. 


\section{Appendix B}

The University of Texas at Tyler

Institutional Review Board

April 9, 2012

Dear Ms. Rivard:

Your request to conduct the study entitled: The Lived Experience of Fathers Whose Children are Diagnosed With A Genetic Disorder is approved as an expedited study, IRB \#Sp2012-75 by The University of Texas at Tyler Institutional Review Board. This approval includes the use of the written informed consent that is attached to this approval letter. Please use this attached form for all persons, and ensure that each participant is able to repeat the purpose of the study, the voluntary nature of it, any risks involved, and who to contact other than you as the PI. In addition, ensure that any research assistants or co-investigators have completed human protection training, and have forwarded their certificates to the IRB office (G. Duke).

\section{Please review the UT Tyler IRB Principal Investigator Responsibilities, and} acknowledge your understanding of these responsibilities and the following through return of this email to the IRB Chair within one week after receipt of this approval letter:

- This approval is for one year, as of the date of the approval letter

- Request for Continuing Review must be completed for projects extending past one year

- Prompt reporting to the UT Tyler IRB of any proposed changes to this research activity

- Prompt reporting to the UT Tyler IRB and academic department administration will be done of any unanticipated problems involving risks to subjects or others

- Suspension or termination of approval may be done if there is evidence of any serious or continuing noncompliance with Federal Regulations or any aberrations in original proposal.

- Any change in proposal procedures must be promptly reported to the IRB prior to implementing any changes except when necessary to eliminate apparent immediate hazards to the subject.

Best of luck in your research, and do not hesitate to contact me if you need any further assistance. 
Appendix B Continued

Sincerely,

Baria Qurke, ORD, PN

Gloria Duke, PhD, RN

Chair, UT Tyler IRB 


\section{Appendix C}

\section{Interview Guide}

\section{Grand Tour Question}

Tell me how you reacted when you learned of your child's genetic disorder (will insert the name of the disorder if known).

\section{Interview Schedule}

○ How were you informed of your child's diagnosis?

- How long has it been?

- How was the disorder explained to you?

- How did you feel immediately after you were told your child's diagnosis?

- How do you feel about your child's diagnosis now?

- What is your understanding of the cause of your child's disorder?

- How do you feel about this?

- How did this information affect you?

- What questions did you have about your child's disorder?

- How well do you feel these questions were answered?

- Were the answers adequate?

- What types of information were provided to assist you in understanding your child's diagnosis?

- What, if any, information did you discover on your own?

- Where did you find the information?

Who was the person that explained the information to you? 


\section{Appendix C Continued}

- Was the information explained in terms you could easily understand?

- What was it like for you to try and understand the information?

- Who, if anyone, was with you when you received the diagnosis?

- How did their reaction affect you?

- Did you discuss the diagnosis with this person?

- Did this person understand the diagnosis?

- How did their understanding of the diagnosis affect you?

- How has your child's diagnosis affected your relationship with your wife or significant other?

○ What, if any, questions do you still have about your child's diagnosis? 


\section{Appendix D}

\section{Demographic Questionnaire}

1. Which category below includes your age?

$$
\begin{array}{l|l}
C & 17 \text { or younger } \\
\hline C & 18-20 \\
\hline C & 21-29 \\
\hline C & 30-39 \\
\hline C & 40-49 \\
\hline C & 50-59 \\
\hline C & 60 \text { or older }
\end{array}
$$

2. What is the highest level of school you have completed or the highest degree you have received?

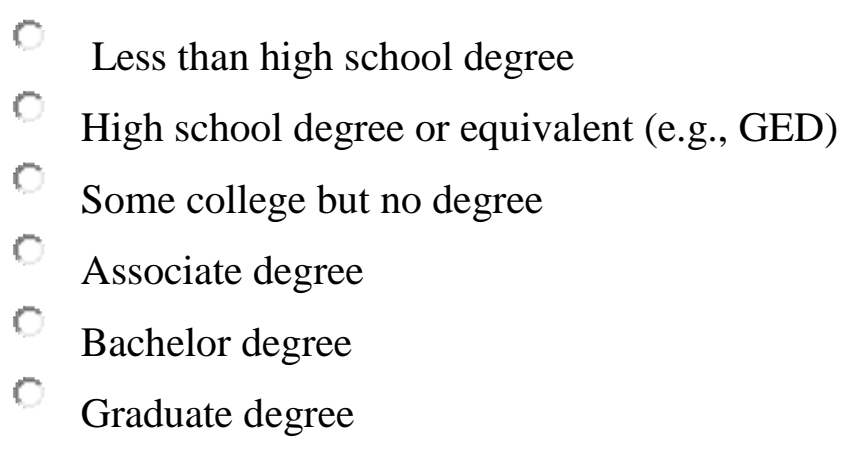

\section{Which of the following categories best describes your employment status?}

\footnotetext{
Employed, working 1-39 hours per week

Employed, working 40 or more hours per week

Not employed, looking for work

Not employed, NOT looking for work

(C) Retired

Disabled, not able to work
} 


\section{Appendix D Continued}

4. Are you White, Black or African-American, American Indian or Alaskan Native, Asian, Native Hawaiian or other Pacific islander, or some other race?

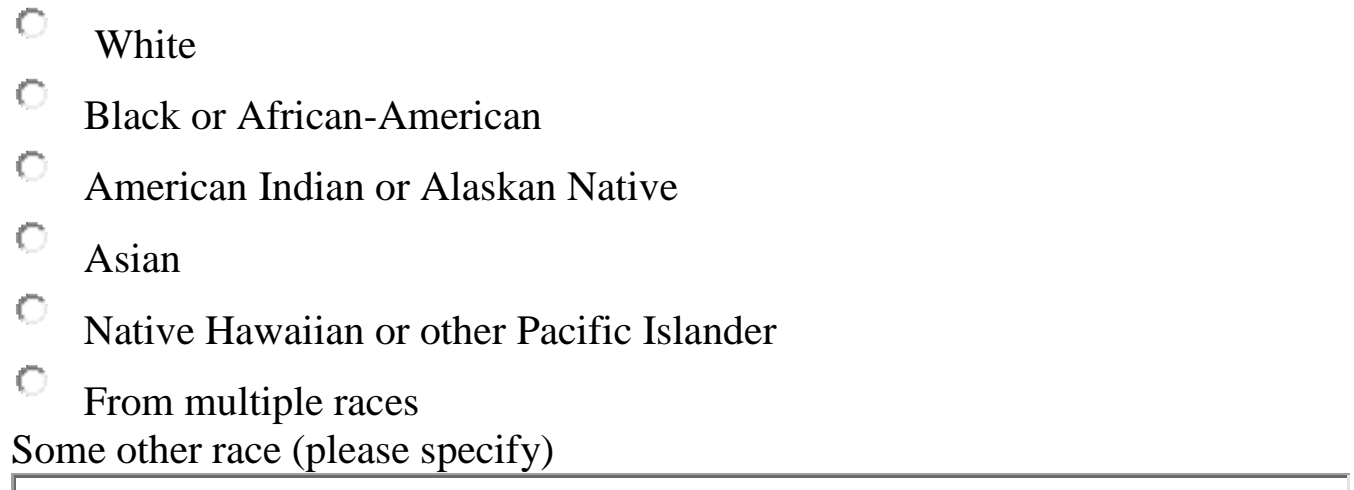

5. Are you now married, widowed, divorced, separated, or never married?

$$
\begin{array}{c|l}
\hline & \text { Married } \\
\hline C & \text { Widowed } \\
\hline C & \text { Divorced } \\
\hline C & \text { Separated } \\
\hline C & \text { Never married }
\end{array}
$$

6. How much total combined money did all members of your HOUSEHOLD earn in 2011? This includes money from jobs; net income from business, farm, or rent; pensions; dividends; interest; social security payments; and any other money income received by members of your HOUSEHOLD that are EIGHTEEN (18) years of age or older. Please report the total amount of money earned - do not subtract the amount you paid in taxes or any deductions listed on your tax return.

$$
\begin{aligned}
& \text { Less than } \$ 20,000 \\
& \text { \$20,000 to } \$ 34,999 \\
& \text { - } \$ 35,000 \text { to } \$ 49,999 \\
& \text { - } \$ 50,000 \text { to } \$ 74,999 \\
& \text { \$75,000 to } \$ 99,999 \\
& \text { \$ } \$ 100,000 \text { to } \$ 149,999 \\
& \$ 150,000 \text { or More }
\end{aligned}
$$




\section{Appendix D Continued}

7. How many children age 17 or younger live in your household?

8. Who resides with you in the household?

Г I live alone

$\Gamma$ Wife/significant other

Child/children

$\Gamma$ Other family

$\Gamma$ Roommate(s)

9. In what ZIP code is your home located? (enter 5-digit ZIP code; for example, 00544 or 94305)

10. What is your child's diagnosis? 


\section{Appendix E}

THE UNIVERSITY OF TEXAS AT TYLER

Informed Consent to Participate in Research

\section{Institutional Review Board \#Sp2012-75}

Approval Date: April 9, 2012

1. Project Title: The Lived Experience of Fathers Whose Children are Diagnosed With A Genetic Disorder

2. Principal Investigator: Mary T. Rivard MSN, RNC-OB

\section{Participant's Name:}

\section{To the Participant:}

You are being asked to take part in this study at The University of Texas at Tyler (UT Tyler). This permission form explains:

- Why this research study is being done.

- What you will be doing if you take part in the study.

This form also talks about the risks that may happen with this study. After talking with the person who asks you to take part in the study, you should be able to:

- Understand what the study is about.

- Choose to take part in this study because you understand what will happen

\section{Description of Project}

The purpose of this study is to describe fathers' experience to the diagnosis of a genetic problem in their child. By understanding these experiences, we will be able to identify ways to assist fathers in similar situations.

\section{Research Procedures}

If you agree to be in this study, we will ask you to do the following things:

You will take part in a personal interview with the researcher. You will be asked questions about your child's diagnosis, how the news was given to you, and your reaction 


\section{Appendix E Continued}

to the diagnosis. The interview is expected to take approximately 45-60 minutes. Following completion of all interviews, you may be asked to clarify any points in question or review the information gained from this study. If you chose to withdraw from the study, this may be done at any time without consequences.

\section{Side Effects/Risks}

This study is not expected to present any physical risks to you. You might become upset talking about these thoughts and feelings. Should this occur you will be given the time you need to calm yourself and we can finish at a later time or stop altogether. Mental health resources will be available and provided for participants as needed. You will be allowed to end the interview at any time if you feel uncomfortable.

\section{Potential Benefits}

This research is expected to provide information needed to develop materials to help fathers of children with genetic problems in hopes that providing this material will increase knowledge and decrease fathers' stress.

\section{Understanding of Participants}

8. I have been given a chance to ask any questions about this research study. The researcher has answered my questions.

9. If I sign this consent form I know it means that:

- I am able to describe the study, how much time it will take, what is expected of me and when it is OK to stop participating in the study.

- I am taking part in this study because I want to. I chose to take part in this study after having been told about the study and how it will affect me.

- I know that I am free to not be in this study. If I choose to not take part in the study, then nothing will happen to me as a result of my choice.

- I know that I have been told that if I choose to be in the study, then I can stop at any time. I know that if I do stop being a part of the study, then nothing will happen to me.

- I will be told about any new information that may affect my wanting to continue to be part of this study. 


\section{Appendix E Continued}

- The study may be changed or stopped at any time by the researcher or by The University of Texas at Tyler.

- The researcher will get my written permission for any changes that may affect me.

10. I have been promised that that my name will not be in any reports about this study unless I give my permission.

11. I also understand that any information collected during this study may be shared as long as no identifying information such as my name, address, or other contact information is provided). This information can include health information. Information may be shared with:

- Organization giving money to be able to conduct this study

- Other researchers interested in putting together your information with information from other studies

- Information shared through presentations or publications

12. I understand The UT Tyler Institutional Review Board (the group that makes sure that research is done correctly and that procedures are in place to protect the safety of research participants) may look at the research documents. These documents may have information that identifies me on them. This is a part of their monitoring procedure. I also understand that my personal information will not be shared with anyone.

13. I have been told about any possible risks that can happen with my taking part in this research project.

14. I also understand that I will not be given money for any patents or discoveries that may result from my taking part in this research.

15. If I have any questions concerning my participation in this project, I will contact the principal researcher: Mary Rivard at (940) 632-0225, or email mrivard@patriots.uttyler.edu

17. If I have any questions concerning my rights as a research subject, I will contact Dr. Gloria Duke, Chair of the IRB, at (903) 566-7023, gduke@uttyler.edu, or the University's Office of Sponsored Research: 


\section{Appendix E Continued}

The University of Texas at Tyler c/o Office of Sponsored Research 3900 University Blvd

Tyler, TX 75799

I understand that I may contact Dr. Duke with questions about research-related injuries.

\section{CONSENT/PERMISSION FOR PARTICIPATION IN THIS}

\section{RESEARCH STUDY}

I have read and understood what has been explained to me. I give my permission to take part in this study as it is explained to me. I give the study researcher permission to register me in this study. I have received a signed copy of this consent form.

Signature of Participant Date

$\begin{array}{ll}\text { Signature of Person Responsible } & \text { Relationship to participant } \\ \text { (e.g., legal guardian) }\end{array}$

Witness to Signature

19. I have discussed this project with the participant, using language that is understandable and appropriate. I believe that I have fully informed this participant of the nature of this study and its possible benefits and risks. I believe the participant understood this explanation. 


\section{BIOGRAPHICAL SKETCH}

\begin{tabular}{l|c|c|c}
\hline $\begin{array}{l}\text { NAME } \\
\text { Rivard, Mary T. }\end{array}$ & \multicolumn{2}{|l}{$\begin{array}{l}\text { POSITION TITLE } \\
\text { Associate Degree Nursing Faculty }\end{array}$} \\
\cline { 1 - 2 } EDUCATION/TRAINING & $\begin{array}{c}\text { DEGREE } \\
\text { (if } \\
\text { applicabl } \\
e)\end{array}$ & MM/YY & \multicolumn{2}{|c}{$\begin{array}{c}\text { FIELD OF } \\
\text { STUDY }\end{array}$} \\
\hline \multicolumn{1}{|l}{ INSTITUTION AND LOCATION } & $\begin{array}{c}\text { BSN } \\
\text { Midwestern State University, Wichita } \\
\text { Falls, Texas }\end{array}$ & $05 / 94$ & Nursing \\
$\begin{array}{l}\text { Midwestern State University, Wichita } \\
\text { Falls, Texas }\end{array}$ & MSN & $05 / 04$ & Nursing Educator \\
$\begin{array}{l}\text { University of Texas at Tyler, Tyler, } \\
\text { Texas }\end{array}$ & Ph.D & Nursing \\
\hline
\end{tabular}

\section{A. Personal Statement}

The study's purpose was to describe the experience of fathers whose children were diagnosed with a genetic disorder. The purpose of this research was to understand how fathers react to this news as a means for development of interventions to enable him to cope. The topic of study came about after a conversation with a father who stated, "How would it make you feel if your daughter had something wrong with her and you knew it was your fault?" In this case, he was referring to the knowledge that his child's disorder was paternally transmitted and his feeling that healthcare professionals did not seem to consider his needs and education a priority.

Traditional parental roles suggest that mothers are responsible for the care and nurturing of children thus, fathers are frequently forgotten in the midst of the conversation. By understanding the impact of diagnosis on a father, his need to understand the diagnosis, his coping abilities, and his distinctive needs, the healthcare profession has the potential to assure the availability of interventions designed to improve outcomes for father's and their families. Nurses, as an integral part of the healthcare team, should be instrumental in ensuring that fathers are included and their needs are met. Being mindful of a father's unique needs must be an integral part of the healthcare plan 
because his role, although different from the mother's, is still an important part of providing for a child's well-being.

\section{B. Positions and Honors}

Nurse's Aide

- 1982 -1992: Wichita General Hospital (WGH), Wichita Falls, TX.

- 1982 -1988: Medical/surgical unit

- 1989 -1991: Psychiatric unit

\section{Clinical Assistant}

- 1992 -1994: Wichita General Hospital (WGH), Wichita Falls, TX. Registered Nurse

- 1994 - 2012: United Regional Hospital (previously WGH and United Regional Health Care System), Wichita Falls, TX.

- Charge nurse/staff nurse, labor and delivery; cross trained to mother/ baby unit, preceptor, and community childbirth instructor.

- 1996 - National Certification Corporation certification, inpatient obstetrics.

ADN Faculty

- 2002 - present: Vernon College Vernon Texas

- Associate Degree Nursing program, Vernon College, Vernon TX, August 2002 - present.

- Medical/surgical clinical instructor

- Obstetric and pediatric nursing classroom and clinical instructor

- Legal and ethical nursing issues instructor (online course)

- Nursing pathophysiology classroom instructor (face to face and online class)

- Instruction includes classroom and internet teaching venues, exam writing, hospital practicum, grading of class work, and student counseling and evaluation.

Memberships

- Sigma Theta Tau; Treasurer Xi Iota chapter, 9/2010 - present

- Association of Women's Health, Obstetric and Neonatal Nurses (AWHONN)

- American Nurse's Association (ANA) and Texas Nurse's Association (TNA)

- One.org

\section{Selected Peer-reviewed Publications}

Bevan, J. L., Senn-Reeves, J. N., Inventor, B. R., Greiner, S. M., Mayer, K. M., Rivard, M. T., \&Hamilton, R. J. (2012). Critical social theory approach to disclosure of genomic incidental findings. Nurs Ethics. doi: $10.1177 / 0969733011433924$ 